Universidade de Brasília - UnB

Faculdade de Economia, Administração, Contabilidade e Ciência da Informação e Documentação (FACE)

Programa de Pós Graduação em Administração (PPGA)

Elzi Ferreira Bittencourt Pereira

\title{
ESTILOS GERENCIAIS PRESENTES NA BIBLIOTECA CENTRAL DE UMA INSTITUIÇÃO FEDERAL DE ENSINO SUPERIOR
}




\section{Estilos Gerenciais Presentes na Biblioteca Central de uma Instituição Federal de Ensino Superior}

Monografia apresentada ao Programa de Pós Graduação em Administração da Faculdade de Economia, Administração, Contabilidade e Ciência da Informação e Documentação (FACE), da Universidade de Brasília, como requisito parcial à obtenção do grau de Especialista em Gestão Universitária.

Orientadora: Profa. Dra. Miramar Ramos Maia Vargas 
Universidade de Brasília - UnB

Faculdade de Economia, Administração, Contabilidade e Ciência da Informação e Documentação (FACE)

Programa de Pós Graduação em Administração (PPGA)

\title{
Estilos Gerenciais Presentes na Biblioteca Central de uma Instituição Federal de Ensino Superior
}

\author{
Elzi Ferreira Bittencourt Pereira
}

Monografia apresentada ao Programa de Pós Graduação em Administração da Faculdade de Economia, Administração, Contabilidade e Ciência da Informação e Documentação (FACE), da Universidade de Brasília, como requisito parcial à obtenção do grau de Especialista em Gestão Universitária.

Banca Examinadora

PROFESSORA DOUTORA MIRAMAR RAMOS MAIA VARGAS

(ORIENTADORA)

PROFESSOR DOUTOR MARCUS VINICIUS SOARES SIQUEIRA (AVALIADOR) 


\section{DEDICATÓRIA}

Ao meu esposo Edmar.

Aos meus filhos Janaína e Edmar Júnior. "Sem vocês meus amores eu não sou ninguém"

Aos meus pais Teófilo e Eudeocina (in memorian), pelos ensinamentos jamais esquecidos. 


\section{AGRADECIMENTOS}

Obrigada Senhor, por estar presente na minha vida me amparando, me protegendo e permitindo que eu continue segurando nas suas mãos.

À minha orientadora Professora Doutora Miramar Ramos Maia Vargas pela constante paciência, dedicação, sabedoria, conhecimento transmitido e por estar sempre disponível para me receber em sua casa durante a realização da presente monografia.

Ao Professor Doutor Marcus Vinícius Soares Siqueira pela gentileza em aceitar participar da banca como avaliador.

À Universidade de Brasília pela minha participação no Curso de Especialização em Gestão Universitária.

Aos meus filhos Janaína e Edmar Júnior, na ordem em que vieram ao mundo. Pela nossa vivência, troca de idéias e apoio irrestrito. Sempre eternamente grata por vocês existirem na minha vida.

Ao meu esposo Edmar, meu maior incentivador, amigo e companheiro de todas as horas, também guerreiro de todas as batalhas que juntos vencemos nestes longos anos.

Ao Diego Luciano da Silva, pela boa vontade em me ajudar com os seus conhecimentos em informática, todas as vezes em que foi solicitado.

Aos colegas da Biblioteca Central que gentilmente participaram da pesquisa.

À Dona Elza, mãe da Professora Miramar, sempre tão gentil e atenciosa comigo. 


\section{RESUMO}

O objetivo deste trabalho foi analisar os estilos gerenciais presentes na biblioteca central de uma universidade pública. A pesquisa foi de caráter exploratório e usou uma abordagem quantitativa, com aplicação da Escala de Avaliação dos Estilos Gerenciais (EAEG). A pesquisa foi conduzida na Biblioteca Central (BCE) da Universidade de Brasília (UnB) e teve por alvo todas as pessoas que trabalhavam na unidade, com exceção das que ocupavam funções gerenciais. Das 134 pessoas que receberam o questionário de pesquisa, 103 responderam. Eliminados os questionários inválidos, trabalhou-se efetivamente com um total de 99 sujeitos. Os dados foram analisados pelo Statistical Package for Social Sciences (SPSS), por meio de estatísticas descritivas e inferenciais. Os resultados apontaram que os três estilos gerenciais investigados - Relacionamento, Tarefa e Situacional - são praticados na BCE. Os testes de comparação das médias das variáveis demográficas quanto aos estilos gerenciais percebidos apontaram que somente as diferenças observadas nas médias dos grupos de faixa etária foram significativas para o Fator Tarefa $(F=0,045)$.

Palavras chaves: Estilos gerenciais; Liderança; Teorias comportamentais. 


\section{LISTA DE FIGURAS}

Figura 1. O Modelo Contingencial de Fiedler .................................................... 20

Figura 2. Modelo Situacional de Liderança de Hersey e Blanchard ........................... 21

Figura 3. Organograma da Biblioteca Central/UnB ............................................... 39 


\section{LISTA DE TABELAS}

\begin{tabular}{|l|l|c|}
\hline Tabela 1 & $\begin{array}{l}\text { Resultados do teste t de Student da variável gênero quanto aos estilos } \\
\text { gerenciais. }\end{array}$ & 47 \\
\hline Tabela 2 & $\begin{array}{l}\text { Resultados do teste ANOVA da variável faixa etária quanto aos estilos } \\
\text { gerenciais }\end{array}$ & 48 \\
\hline Tabela 3 & $\begin{array}{l}\text { Resultados do Statistical Package for Social Sciences (SPSS) da } \\
\text { variável categoria funcional quanto aos estilos gerenciais. }\end{array}$ & 48 \\
\hline Tabela 4 & $\begin{array}{l}\text { Resultados do teste ANOVA da variável escolaridade quanto aos } \\
\text { estilos gerenciais }\end{array}$ & 49 \\
\hline Tabela 5 & $\begin{array}{l}\text { Resultados do Statistical Package for Social Sciences (SPSS) da } \\
\text { variável categoria funcional quanto aos estilos gerenciais. }\end{array}$ & 50 \\
\hline Tabela 6 & $\begin{array}{l}\text { Resultados do Statistical Package for Social Sciences (SPSS) da } \\
\text { variável categoria funcional quanto aos gerenciais. }\end{array}$ & 50 \\
\hline Tabela 7 & $\begin{array}{l}\text { sultados do teste ANOVA da variável tempo de serviço da BCE } \\
\text { quanto aos estilos gerenciais. }\end{array}$ & 54 \\
\hline Tabela 8 & Índice de Consistência Interna dos Itens da EAEG & 54 \\
\hline Tabela 9 & Média e Desvio Padrão dos Estilos Gerenciais & 54 \\
\hline
\end{tabular}




\section{LISTA DE QUADROS}

Quadro 1. Definições de Liderança ... ................................................................. 14

Quadro 2. Quadro Comparativo da Teoria X e Y de Mc Gregor............................. 18

Quadro 3. Estilos Gerenciais da Teoria do Caminho-Objetivo................................ 22

Quadro 4. Características dos Líderes Transacionais e Transformacionais.............. 24

Quadro 5. Estilos Gerenciais e Abordagens Teóricas de Liderança.......................... 25

Quadro 6. Significados e Objetivos de Habilidade Gerencial................................... 28

Quadro 7. Mitos e Verdades Sobre a Função do Dirigente..................................... 30

Quadro 8. Mitos sobre a Qualidade para o Exercício Gerencial............................. 31

Quadro 9. Divergências entre as Perspectivas Clássicas e Modernas...................... 32 


\section{SUMÁRIO}

$\begin{array}{ll}\text { Introdução } & 11\end{array}$

Capítulo I - Fundamentação Teórica $\quad 14$

1.1. A Multiplicidade do Conceito de Liderança? 14

1.2. Abordagens de Liderança 15

1.2.1. Teoria dos Traços 15

1.2.2. Teorias Comportamentais 16

1.2.2.1 Estudos de Ohio State University 16

1.2.2.2. Estudos da University of Michigan 17

$\begin{array}{ll}\text { 1.2.2.3. Teoria de Mc Gregor } & 17\end{array}$

1.2.3. Teorias Contigenciais (ou Situacionais) 19

1.2.3.1. O Modelo Contingencial de Fiedle 19

1.2.3.2. Teoria da Liderança Situacional de Hersey e Blanchard 20

1.2.3.3. Teoria do Caminho-Objetivo 22

1.2.4. Liderança transacional $x$ transformacional 23

1.2.5. Liderança Visionária 24

1.3. Relacionamento, Tarefa e Situação: integrando grandes estilos 24

1.4. Função Gerencial 26

1.5. Pesquisas Nacionais sobre Liderança 33

Capítulo 2 - Metodologia da Pesquisa 38

2.1. Tipo de Pesquisa 38

2.2. Contexto da Pesquisa 38

2.3. Participantes da Pesquisa 40

2.4. Instrumento da Pesquisa 40

2.5. Procedimentos de Coleta de Dados 41

2.6. Procedimentos de Análise de Dados 41

Capítulo 3 - Apresentação e Discussão dos Resultados 42

3.1. Validação da Estrutura Empírica do Instrumento 42

3.2. Percepção dos Estilos Gerenciais da Biblioteca Central 43

$\begin{array}{ll}\text { Conclusão } & 49\end{array}$

Referências 


\section{INTRODUÇÃO}

Liderança é um tema que sempre despertou o interesse de estudiosos, pesquisadores e pessoas que trabalham no dia-a-dia das organizações. Diferentes áreas do conhecimento, como por exemplo, a Administração e a Psicologia, respondem pelo desenvolvimento do tema. Essas áreas têm contribuído significativamente para a expansão do conhecimento hoje existente sobre o assunto.

Segundo Chowbdury (2003), o ativo mais valioso do líder do século XXI será o amplo conhecimento da cultura, idiomas e assuntos diversos que agregarão valores ao seu potencial. Para que as organizações não sofram, os líderes serão indivíduos pessoalistas e manterão seu sistema de comunicação com total eficiência, criando ambientes e condições desejáveis para que os liderados se comprometam com as estratégias e decisões a serem tomadas objetivando entusiasmos para atingirem metas comuns à organização.

Motta (1996) destaca que as organizações são diferentes e, para cada uma delas é necessário um novo aprendizado gerencial. No entanto, afirma o autor, existem comportamentos gerenciais comuns entre aqueles que desempenham essa função com sucesso; pode-se dizer que esses comportamentos provêm de habilidades gerenciais típicas que podem ser assimiladas. Para o autor, se os dirigentes de grandes organizações aprenderam a se comportar de certa maneira, talvez não tenha sido por mero acaso, mas sim por imposição de uma realidade organizacional que possui padrões comuns. Os estudos de liderança envolvem a compreensão dessa realidade e a sistematização desses comportamentos típicos que contribuem para o alcance de eficácia na ação gerencial.

Blake e Mouton (1978) lembram que todas as organizações apresentam algumas características que são universais. Essas características estão presentes em menor ou maior grau em cada organização, independentemente do tipo de produto ou serviço que ela ofereça. A administração eficaz dessas características, afirmam Blake e Mouton (1978), reflete na produção eficiente da organização como um todo.

Uma das características universais discutida por Blake e Mouton envolve a questão da liderança. Ela está presente em todos os tipos de organizações, inclusive em uma universidade pública que é também uma forma de organização. Como toda organização, a universidade possui diferentes unidades que estão sob a responsabilidade de pessoas que ocupam funções gerenciais. A Biblioteca Central é uma das unidades que compõe a estrutura orgânica de uma universidade e como tal, agrega também em seu quadro pessoas com esse perfil. 
No contexto acadêmico, em razão da nova política de modernização do ensino superior, como resultado das reformas propostas pelo Estado, ainda é forte a discussão sobre gerência na administração pública. A partir da nova ótica da modernização do ensino público, sinaliza-se uma constante preocupação com a qualificação dos administradores-gestores para responderem as demandas que a sociedade solicita. Para tanto, torna-se necessária a existência de gestores bem preparados.

Silva, Cunha e Possamai (2001) lembram que as pessoas que exercem cargos gerenciais são responsáveis pela formulação, articulação e execução das estratégias e movimentos táticos das organizações. Elas não apenas definem as grandes estratégias da organização, mas também articulam os vários subsistemas organizacionais visando atingir determinados objetivos. As habilidades gerenciais determinam o sucesso da organização.

Observa-se, assim, que a função gerencial desempenha um papel muito importante no sucesso de qualquer organização, independentemente do tipo de produto ou serviço oferecido. No caso específico da biblioteca central, uma das unidades administrativas que compõe uma Instituição Federal de Ensino Superior (IFES), a importância estratégica da função gerencial não é menor. Essa constatação estimulou o interesse pelo estudo do seguinte problema de pesquisa: "Que estilos gerenciais predominam na biblioteca central de uma Instituição Federal de Ensino Superior (IFES)?”

Para obter resposta à questão formulada no problema de pesquisa foram traçados os seguintes objetivos:

\section{Objetivo Geral}

- Analisar os estilos gerenciais presentes na biblioteca central de uma Instituição Federal de Ensino Superior (IFES).

\section{Objetivos Específicos}

- Fazer uma revisão da literatura sobre o tema "liderança", com ênfase em "estilos gerenciais".

- Identificar os estilos gerenciais presentes na biblioteca central de uma IFES, comparando-os com os descritos pela literatura.

A relevância do tema encontra suporte em autores como Marra e Melo (2005), os quais lembram que, no contexto acadêmico, os técnicos administrativos que desempenham a função gerencial também administram a insatisfação dos subordinados, os conflitos 
interpessoais, lidam com mão-de-obra não qualificada, recebem cobranças dos superiores e também se julgam incompreendidos. Muitas vezes, assim como acontece com os professoresgerentes, os servidores técnicos administrativos da universidade demonstram não ter as habilidades necessárias para lidarem com conflitos e se mostram despreparados para o exercício da função gerencial.

Silva, Cunha e Possamai (2001) observam que embora vários estudiosos tenham constatado que muitos programas de desenvolvimento gerencial se mostravam inadequados, pouco esforço tem sido feito para modificar essa situação. As críticas, afirmam esses autores, ficam mais fortes e a literatura fica mais escassa quando se trata de gerentes de unidades de instituições de ensino superior.

O trabalho de Silva, Cunha e Possamai (2001) deu ênfase às funções gerenciais desempenhadas por membros do corpo docente de uma Instituição Federal de Ensino Superior. Marra e Melo (2005) também evidenciam as práticas gerenciais adotadas por professores, porém algumas delas assemelham-se as utilizadas pelos gerentes administrativos.

Ao contrário de Silva, Cunha e Possamai (2001) que também desenvolverem uma pesquisa sobre liderança no contexto acadêmico, o foco do presente trabalho não é centrado nos membros do corpo docente da universidade, mas sim nas pessoas da área técnicoadministrativa que exercem funções gerenciais. Comparar os estilos gerenciais exercidos na unidade administrativa de uma universidade com aqueles discutidos na literatura, pode contribuir para que se conheça um pouco mais sobre como a liderança é exercida dentro da estrutura de uma organização acadêmica.

O presente trabalho está estruturado em quatro capítulos. O primeiro capítulo traz uma breve revisão de literatura sobre Liderança, incluindo algumas pesquisas nacionais realizadas sobre o tema. O segundo capítulo aborda a metodologia utilizada para a realização da presente pesquisa. Os resultados da pesquisa serão apresentados e discutidos no terceiro capítulo. O último capítulo apresenta a conclusão do trabalho. 


\section{CAPÍTULO 1 - FUNDAMENTAÇÃO TEÓRICA}

Neste Capítulo será feita uma breve revisão da literatura de Liderança, apresentando conceitos, abordagens, estilos e algumas pesquisas realizadas sobre o tema no Brasil.

\subsection{A Multiplicidade do Conceito de Liderança}

Existem inúmeras definições de liderança presentes na literatura. Há décadas, autores como Katz e Kahn (1987) chamavam a atenção para o fato de que entre os cientistas sociais não existia muito acordo quanto a uma definição específica e mesmo quanto à significação teórica dos processos de liderança.

Os conceitos de liderança variam em razão dos diferentes contextos em que são aplicados. Sob essa ótica, Bass (1990) e outros autores destacam que liderança pode ser vista como: a) uma característica pessoal; b) a arte de induzir à obediência; c) a forma de convencer pessoas ou de exercer influência; d) um instrumento para se alcançar objetivos; e) o resultado de uma interação; f) um papel diferenciado nos processos grupais e g) uma forma de estruturação; h) uma relação de poder; i) um instrumento para alcançar metas.

Stogil (1974 apud BERGAMINI, 1994) esclarece que embora o termo liderança venha sendo utilizado há, aproximadamente, duzentos anos na língua inglesa, ele é bem mais antigo, acreditando-se que tenha aparecido por volta do ano 1300 D.C.

Bergamini (1994) reuniu várias definições de liderança encontradas na literatura. Algumas dessas definições são apresentadas no Quadro 1:

\begin{tabular}{|c|l|}
\hline Autor & \multicolumn{1}{c|}{ Definição } \\
\hline $\begin{array}{c}\text { Hemphill e Coons } \\
(1957)\end{array}$ & $\begin{array}{l}\text { Liderança é o comportamento de um indivíduo quando está dirigindo as atividades de } \\
\text { um grupo em direção a um bem comum. }\end{array}$ \\
\hline $\begin{array}{c}\text { Jacobs } \\
(1970)\end{array}$ & $\begin{array}{l}\text { Liderança é uma interação entre as pessoas na qual uma apresenta informação de um } \\
\text { tipo de tal maneira que os outros se tornam convencidos de que seus resultados serão } \\
\text { melhorados caso se comportem de maneira sugerida ou desejada. }\end{array}$ \\
\hline $\begin{array}{c}\text { Katz e Kahn } \\
(1978)\end{array}$ & $\begin{array}{l}\text { Liderança é o incremento da influência sobre e acima de uma submissão mecânica com as } \\
\text { diretrizes rotineiras da organização. }\end{array}$ \\
\hline $\begin{array}{c}\text { Zago } \\
(1982)\end{array}$ & $\begin{array}{l}\text { É o uso da influência simbólica e não coercitiva para dirigir e coordenar as atividades } \\
\text { dos membros de um grupo organizado para a realização de objetivos do grupo. }\end{array}$ \\
\hline $\begin{array}{c}\text { Rouch e Behline } \\
(1984)\end{array}$ & $\begin{array}{l}\text { Liderança é o processo de influenciar as atividades de um grupo organizado na } \\
\text { realização de um objetivo. }\end{array}$ \\
\hline
\end{tabular}

Quadro 1: Definições de Liderança

Adaptado de Bergamini (1994) 
Para Jesuíno (1987 apud BERGAMINI, 1994), existem quase tantas definições diferentes de liderança como autores que a tentaram definir. Isso faz com que haja uma sobreposição entre as diferentes definições permitindo senão uma definição universalmente aceita, mas uma caracterização mínima de conceito.

Hampton (1990) esclarece que parece haver dois significados básicos diferentes de liderança, na medida em que ela é aplicada ao problema da administração das organizações. Um desses significados oferece uma visão mais ampla e abrange o problema de se definir, construir e manter o caráter e a cultura distintos de uma organização. O segundo significado está associado a uma noção de liderança como processo interpessoal por meio do qual os gerentes influenciam os empregados a executarem as tarefas que lhes foram previamente fixadas.

Maximiniano (1999) define liderança como um processo de conduzir as ações ou de influenciar o comportamento e a mentalidade de outras pessoas. Para o autor, a proximidade física ou temporal não é importante nessa definição. Um cientista pode ser influenciado por um colega de profissão que nunca viu ou mesmo que viveu em outra época. Da mesma forma, líderes religiosos são capazes de influenciar adeptos que estão muito longe e que têm pouquíssima chance de vê-los pessoalmente.

Na visão de Chowdhury (2003), líder é alguém que se coloca a frente, tem coragem, capacidade e credibilidade para inspirar a mudança em vários níveis.

\subsection{As Abordagens de Liderança}

Nesta seção serão apresentadas, de forma breve, algumas das principais abordagens que marcam a evolução dos estudos de Liderança ao longo do tempo.

\subsubsection{Teoria dos Traços}

Segundo Bergamini (1994), os primeiros estudos sobre teoria dos traços foram desenvolvidos no início do século XX. Naquela época, já havia a preocupação em identificar as diferentes características de personalidade especiais responsáveis pelo desempenho do papel de liderança e manutenção da posição de líder, que contribuíssem para diferenciar os líderes dos liderados. Traços sociais, físicos, intelectuais, de personalidade, energia física, necessidade de poder e outros estavam entre os traços estudados.

Stogdill e Mann (1974 apud BERGAMINI, 1994) utilizaram aproximadamente 124 projetos realizados no período entre 1904 a 1948 e, após revisão, consideraram 34 traços de personalidade como características típicas de líderes eficazes. Alguns desses traços envolviam: 
sociabilidade e habilidades interpessoais, auto-confiança, ascendência e domínio, participação nas trocas sociais, fluência verbal, equilíbrio emocional e controle, busca de responsabilidade e outros.

Bergamini (1994) lembra, todavia, que muitas das pesquisas feitas para se determinar os traços responsáveis pela eficácia dos líderes não tiveram comprovação na prática. Os teóricos não acreditavam na existência de traços consistentes e únicos que pudessem ser aplicados a todos os líderes eficazes. Esse resultado fez com que os pesquisadores abandonassem o interesse pelo estudo dos traços.

Robbins (2001) assinala algumas razões que determinaram as falhas dessa tendência em se caracterizar a eficácia de um líder em função dos seus traços:

- não foram consideradas as necessidades dos seguidores, os mesmos eram considerados como instrumentos a serem alcançados;

- os objetivos dos estudos sobre os traços de personalidade do líder não foram alcançados; a relação causa e efeito no comportamento do líder não foi totalmente explicada;

- não foram considerados os elementos situacionais no processo de liderança.

\subsubsection{Teorias Comportamentais}

Como os estudos sobre os traços não apresentaram resultados precisos, os pesquisadores iniciaram outra linha de investigação que buscava explicar a eficácia do líder com base no seu comportamento.

Para Melo (2001), essa tendência desenvolveu-se a partir da preocupação sobre as ações dos líderes como fator de influência para a motivação, produtividade e a qualidade do desempenho dos seguidores. Abaixo, algumas representantes dessa abordagem de liderança:

\subsubsection{Estudos da Ohio Stade University}

Segundo Melo (2001), os estudos de Ohio iniciaram-se no período pós-guerra mundial, visando conhecer as características independentes no comportamento do líder em mais de 1800 afirmações. O resultado da pesquisa identificou apenas dois fatores determinantes no comportamento de liderança denominados de Estrutura Inicial e Consideração.

Melo (2001) explica que o primeiro fator - Estrutura Inicial - considera a possibilidade do líder para definir e estruturar o seu papel e dos subordinados com base na execução das 
metas. O segundo - Estrutura de Consideração - é descrito por meio de amizade, confiança mútua, respeito às idéias e cuidado com os sentimentos.

\subsubsection{Estudos da University of Michigan}

Os estudos da University of Michigan, narra Melo (2001), iniciaram-se em período próximo aos estudos da Ohio State University. Ambos tinham igual objetivo - buscar identificar o comportamento do líder para desenvolver um desempenho eficaz. Os estudos da University of Michigan também evidenciaram apenas dois fatores determinantes:

- Orientação para o Empregado - o líder possui estilo que prioriza as relações interpessoais, facilitação e orientação para os seguidores obtendo maior produtividade e satisfação do grupo.

- Orientação para a produção - o estilo do líder enfatiza as práticas de trabalho e considera que os empregados servem apenas para atingir os objetivos organizacionais.

Para Hampton (1990), embora o estilo do líder orientado para as pessoas priorize a consideração, preocupação, o bom relacionamento com as pessoas, a satisfação e a coesão do grupo, ele não contribui para o aumento da produtividade.

\subsubsection{Teoria de McGregor}

Motta (2002) explica as teorias "X" e "Y" propostas por Douglas McGregor, em que os conceitos de motivação e liderança se relacionam às diferenças existentes na natureza humana, suas motivações correspondem a diferentes estilos de liderança.

A teoria " $X$ " é a teoria gerencial convencional segundo a Escola de Administração Científica, explica Motta (2002). A ideologia da teoria "X" afirma que o ser humano é avesso ao trabalho e o evitará sempre que puder e, por conseguinte, a administração precisa incrementar a produtividade, os esquemas de incentivos e denunciar a restrição voluntária. McGregor, se baseia no conceito de homo economicus e na visão utilitarista do ser humano predominante no século XIX para explicitar a sua teoria gerencial em que os gerentes e administradores são os únicos responsáveis pela organização dos fatores de produção e devem estabelecer produtos explícitos de comportamento e monitorá-los, de forma escrita, o controle social burocrático, baseando-se nas regras e em outros elementos formais. Trata-se de um estilo de gestão centralizadora e autoritária. A intervenção e o controle gerencial são 
fundamentais para garantir a produtividade e eficiência. Sem o controle, o ser humano tende a ser passivo e resistente em colaborar para atingir dos objetivos organizacionais.

Contrapondo-se à teoria "X", que se baseia no exercício da autoridade racional-legal, a outra proposta de McGregor é a teoria "Y". Nessa teoria, explica Motta (2002), McGregor introduziu componentes pessoais na relação de trabalho com forte apelo às qualidades do líder, em que os mesmos tentam ajudar os subordinados a aprenderem como administrar a si mesmos.

Para Motta (2002), as teorias "X" e "Y" serviram de contribuição para que os teóricos Abraham Maslow e Frederick Herzberg estudassem os modos pelos quais a autonomia pessoal e a participação em grupos poderia encorajar o crescimento, o desenvolvimento e a satisfação do empregado, surgindo a partir de então, reformulações nas tarefas e processos de trabalho, com uma maior descentralização da autoridade e concessão de autonomia aos indivíduos que permitiram o surgimento de novos trabalhos sobre liderança. O Quadro 2 mostra a comparação entre as teorias "X" e "Y":

\begin{tabular}{|l|l|}
\hline \multicolumn{1}{|c|}{ Teoria X } & \multicolumn{1}{c|}{ Teoria Y } \\
\hline As pessoas são preguiçosas e indolentes. & $\begin{array}{l}\text { As pessoas gostam do trabalho que exercem e } \\
\text { são esforçadas e dedicadas. }\end{array}$ \\
\hline As pessoas tendem a evitar o trabalho. & $\begin{array}{l}\text { As pessoas consideram o trabalho como algo } \\
\text { natural a ser realizado. }\end{array}$ \\
\hline As pessoas evitam a responsabilidade para & $\begin{array}{l}\text { As pessoas podem se controlar e assumir } \\
\text { responsabilidades. }\end{array}$ \\
\hline sentirem-se seguras. & \multicolumn{2}{|c|}{} \\
\hline As pessoas são ingênuas e sem iniciativa. & As pessoas são criativas e competentes. \\
\hline
\end{tabular}

Quadro 2 - Quadro Comparativo da Teoria X e Y de McGregor

Fonte: Adaptado de Motta (2002. p. 77)

Para Motta (2002), no contexto atual a liderança é vista como um processo social, grupal e interativo e não como um fenômeno individual em que as articulações políticas de uma pessoa prevalecem no processo decisório. Nessa nova visão, o poder de um líder é compartilhado com o grupo, o poder baseia-se nos recursos dos liderados resultando em menor submissão e maior aliança. Os liderados são estimulados a terem mais iniciativas para buscarem os resultados que precisam ser alcançados. 


\subsubsection{Teorias Contingenciais (ou Situacionais)}

\subsubsection{O Modelo Contingencial de Fiedle}

As teorias contingenciais ou situacionais procuraram reconciliar as diferenças encontradas nas pesquisas relacionadas às teorias comportamentais com as variáveis que interferem no processo de liderança.

Segundo Hampton (1990), Fred Fiedler, considerado o principal pesquisador de liderança, criou meios para medir estilos e situações sugerindo que a combinação de ambos era satisfatória. Tornou-se a mais abrangente abordagem situacional na liderança denominada de "O modelo de Fiedler", identificando três variáveis determinantes da liderança, definidas como:

- Relações líder-membro - O grau de intimidade, confiança e respeito dos subordinados em relação ao líder (avaliadas como boas ou deficientes).

- Estrutura da tarefa - O grau que as tarefas do cargo do subordinado são estruturadas (avaliadas como alta ou baixa).

- Poder de posição - O grau de influência exercida pelo líder sobre as variáveis como orientação, demissão, disciplina, promoções e aumentos de salário (avaliado como forte ou fraco).

Segundo Hampton (1990), para Fiedler o controle e a influência do líder dependem da sua relação com os membros, da estrutura do cargo e do poder de posição. Fiedler e depois outros pesquisadores analisaram dezenas de situações, comparando os estilos orientados de liderança para as pessoas com os voltados para as tarefas. $\mathrm{O}$ resultado apontou oito categorias situacionais que os grupos orientados para a tarefa tendem a desempenhar melhor os seus papéis em situações muito favoráveis ou muito desfavoráveis. Também foi constatado que os grupos orientados para as pessoas desempenhavam melhor em situações moderadamente favoráveis. Apesar de Fiedler não ter conseguido identificar todas as variáveis situacionais da liderança, os pesquisadores após vários testes concluíram que as variáveis identificadas contribuem significativamente para o entendimento dos fatores situacionais.

A Figura 1, apresentada a seguir, ilustra o estilo de liderança associado à favorabilidade situacional, de acordo como o modelo de Fiedler: 


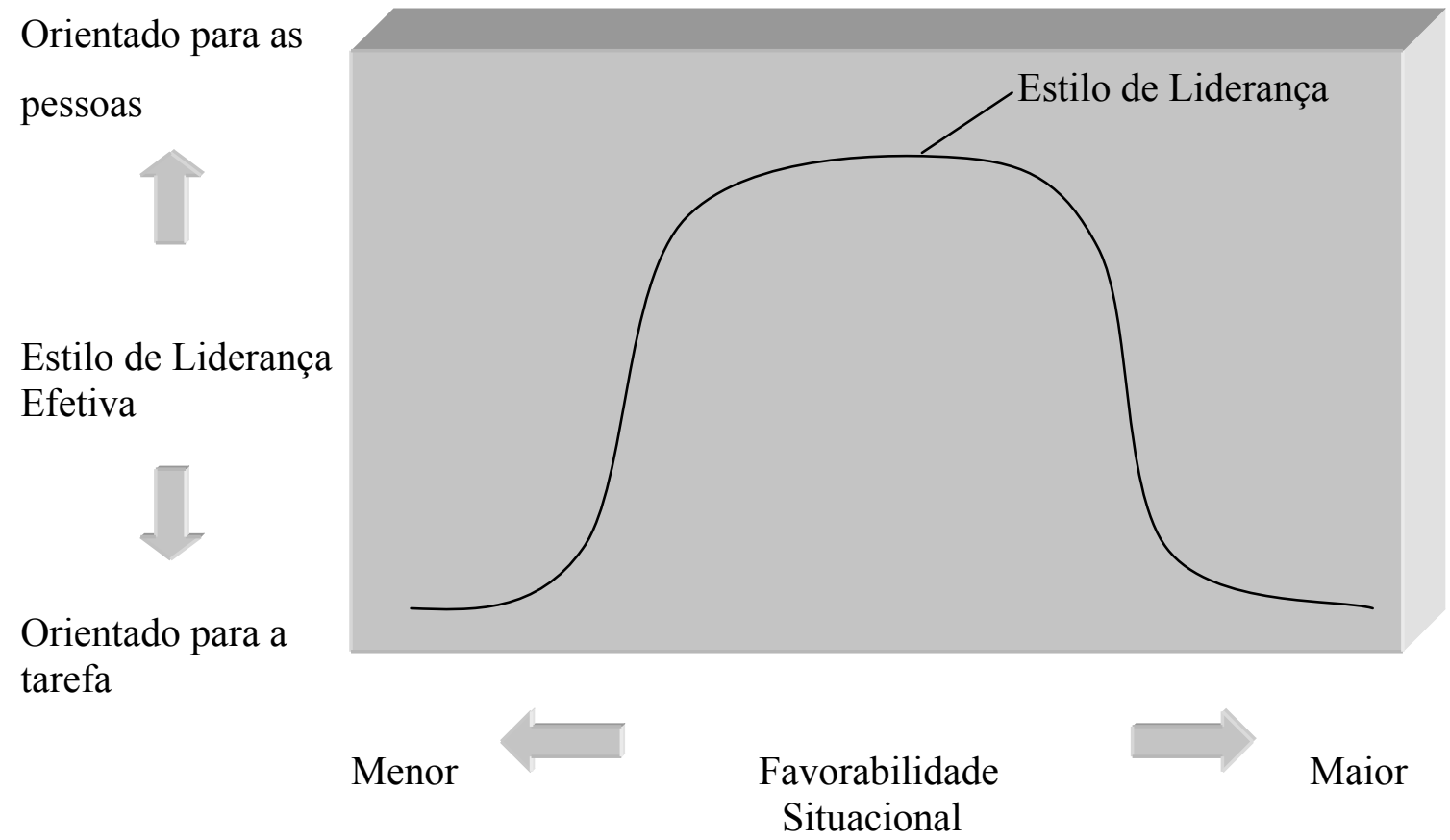

Figura 1 - O Modelo Contingencial de Fiedler

Fonte: Hampton (1990, p. 221)

\subsubsection{Teoria da Liderança Situacional de Hersey e Blanchard}

Stoner e Freeman (1999) lembram que outra importante teoria que compõe o grupo das teorias situacionais é a proposta por Hersey e Blanchard. Nessa teoria, Hersey e Blanchard afirmam que o estilo mais eficaz de liderança varia de acordo com a "maturidade" dos subordinados. Os autores definem maturidade não como idade ou estabilidade emocional, mas como desejo de realização, disposição para aceitar responsabilidades e capacidade e experiência relacionadas à tarefa. Os objetivos e o conhecimento dos seguidores são variáveis importantes na determinação de um estilo eficaz de liderança.

Hersey e Blanchard, explicam Stoner e Freeman (1999), acreditam que os administradores variam seus estilos de liderança em função de quatro fases (uma espécie de ciclo de vida) que acompanham o amadurecimento dos subordinados:

- Fase 1 - Momento inicial da entrada dos subordinados na organização. Nela, é mais natural que o estilo gerencial seja voltado para a tarefa, pois os subordinados precisam ser instruídos em suas tarefas e se familiarizarem com as regras e os procedimentos da organização. 
- Fase 2 - Nessa fase, ainda é essencial que o estilo seja voltado para a tarefa, pois os subordinados podem ainda estarem inseguros e não desejosos de assumir, sozinhos, toda a responsabilidade pelo serviço.

- Fase 3 - A capacidade e a maturidade dos subordinados crescem nessa fase. $\mathrm{O}$ gerente não precisará ser mais tão diretivo para a tarefa, mas é necessário dar apoio e mostrar consideração aos subordinados para que eles mantenham o interesse por mais responsabilidades.

- Fase 4 - Nessa fase os subordinados estão bem mais independentes e não esperam um relacionamento muito direcionador por parte do gerente.

A Figura 2 ilustra o modelo de Hersey e Blanchard:

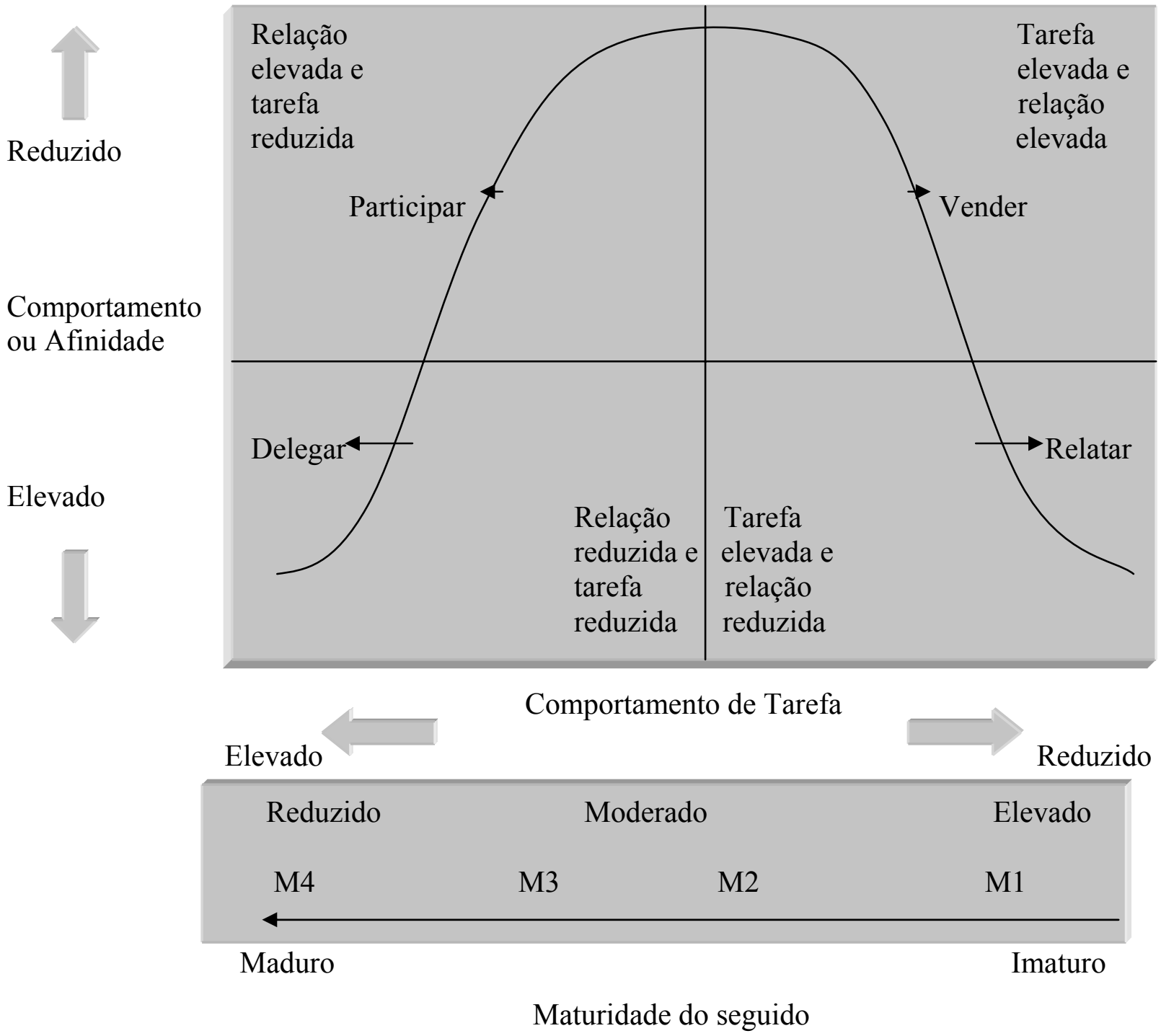

Figura 2 - Modelo Situacional de Liderança de Hersey e Blanchard

Fonte: Hampton (1990, p. 225) 


\subsubsection{Teoria do Caminho-Objetivo}

De acordo com Wagner e Hollenberg (2002) a Teoria do Caminho-Objetivo ainda é a mais abrangente da liderança e a que melhor explica o modelo transacional. Embora nem todas as variáveis tenham sido testadas, o seu arcabouço é excelente para gerar, testar e entender as complexidades do processo de liderança. Esclarece que o principal objetivo do líder é motivar os seus seguidores definindo as metas e fornecendo a direção e apoio necessário para que as metas e os objetivos gerais do grupo sejam compatíveis. Ela é baseada na Teoria de Expectativa da Motivação e enfatiza três variáveis motivacionais: valências, instrumentalidades e expectativas em que os líderes podem influenciar por seus comportamentos ou estilos de decisões.

Wagner e Hollenberg (2002) explicam que a Teoria do Caminho-Objetivo propõe quatro estilos de comportamento que permitem ao líder manipular as variáveis motivacionais: liderança diretiva, encorajadora, participativa e orientada para a realização. Esses estilos constituem-se tanto de comportamentos como o da estrutura iniciadora, como do estilo de decisão e de abordagem autoritária, em que a eficácia do líder em qualquer situação depende dos seus seguidores. Ela reconhece que as características situacionais podem tornar o comportamento do líder desnecessário ou impossível. O Quadro 3 apresenta os quatro estilos gerenciais propostos pela Teoria do Caminho-Objetivo:

\begin{tabular}{|c|l|}
\hline Estilo & \multicolumn{1}{|c|}{ Descrição } \\
\hline Liderança diretiva & $\begin{array}{l}\text { O líder é autoritário. Os subordinados sabem exatamente o que é } \\
\text { esperado deles e olíder e fornecem direções específicas. } \\
\text { Os subordinados não participam da tomada de decisões. }\end{array}$ \\
\hline Liderança encorajadora & $\begin{array}{l}\text { O líder é amistoso, acessível e demonstra uma } \\
\text { preocupação genuína com os subordinados. }\end{array}$ \\
\hline Liderança participativa & $\begin{array}{l}\text { O líder pede e usa as sugestões dos subordinados, mas } \\
\text { ainda toma as decisões. }\end{array}$ \\
\hline Liderança orientada para a realização & $\begin{array}{l}\text { O líder fixa metas desafiadoras para os subordinados e } \\
\text { demonstra confiança de que eles atingirão essas metas. }\end{array}$ \\
\hline
\end{tabular}

Quadro 3 - Estilos Gerenciais da Teoria do Caminho-Objetivo

Fonte: Wagner e Hollenbeck (2002. p. 262).

Wagner e Hollenberg (2002) após testarem pequenos componentes do modelo da teoria do caminho-objetivo, constataram as seguintes evidências: 
- O comportamento do líder diretivo como liderança orientada para as tarefas produz satisfação e desempenho elevado, somente entre seguidores que sentem maior necessidade de clareza nas tarefas a serem executadas.

- O comportamento do líder encorajador como liderança orientada às pessoas resulta em satisfação do seguidor, somente em situações nas quais a tarefa esteja altamente estruturada.

- O comportamento do líder participativo resulta em satisfação em situações nas quais a tarefa não é rotineira, somente, para seguidores que não são autoritários.

- O comportamento do líder orientado para a realização resulta em melhoria moderada do desempenho, somente quando os seguidores são dedicados às metas.

\subsubsection{Liderança Transacional $x$ Transformacional}

Segundo Melo (2001) a liderança transacional tem como característica o estilo orientado para as tarefas indicando o que deve ser feito e como fazê-lo, apresenta divergência de acordo com a característica dos seus seguidores. O líder motiva, acompanha, orienta os seguidores no que deve ser feito, como fazê-lo e distribui recompensa. A liderança transformacional estimula, instiga e desperta nos seus seguidores a necessidade de um esforço maior para cumprimento das metas.

Para Nord e Fox (1996 apud MELO, 2001) esses líderes por terem visão própria sobre as necessidades da organização, exercem forte influência sobre os indivíduos e apresentam restrições dos estudiosos em Comportamento Organizacional tendo em vista considerarem apenas o líder e não a relação entre os líderes e seguidores.

Conforme Melo (2001), as atuais abordagens dos estudos sobre liderança, ainda são as mesmas apresentadas na sua origem em que o exame das características pessoais dos líderes e a afetividade da liderança eram o foco da abordagem dos traços. Alguns estudiosos definem a liderança transformacional como "liderança de destaque" que objetiva diferenciar os líderes extraordinários dos comuns.

Ainda Melo (2001) os líderes transacionais e transformacionais têm abordagens semelhantes para resolução de tarefas, porém a liderança transformacional utiliza-se da transacional para obtenção de índice desejável de esforço e desempenho dos subordinados. $\mathrm{O}$ Quadro 4 apresenta as características dos líderes transacionais e transformacionais: 


\begin{tabular}{|l|l|}
\hline \multicolumn{1}{|c|}{ Líder Transacional } & \multicolumn{1}{|c|}{ Líder Transformacional } \\
\hline $\begin{array}{l}\text { Recompensa contingente. Negocia troca de } \\
\text { recompensas por esforço, promete recompensas por } \\
\text { bom desempenho, reconhece realizações }\end{array}$ & $\begin{array}{l}\text { Carisma. Apresenta visão e sentido de missão, } \\
\text { instila orgulho, obtém respeito e confiança. }\end{array}$ \\
\hline $\begin{array}{l}\text { Administração por exceção (ativa). Observa e } \\
\text { procura desvios das regras e padrões, toma medidas } \\
\text { corretivas. }\end{array}$ & $\begin{array}{l}\text { Inspiração. Comunica expectativas elevadas, } \\
\text { utiliza símbolos para concentrar esforços, expressa } \\
\text { objetivos importantes de maneira simples. }\end{array}$ \\
\hline $\begin{array}{l}\text { Administração por exceção (passiva). Apenas } \\
\text { intervém quando os padrões não são cumpridos. }\end{array}$ & $\begin{array}{l}\text { Estimulo intelectual. Promove a racionalidade, a } \\
\text { inteligência e a solução cuidadosa de problemas. }\end{array}$ \\
\hline $\begin{array}{l}\text { "Laissez-faire". Abdica-se de responsabilidades, } \\
\text { evita tomar decisões. }\end{array}$ & $\begin{array}{l}\text { Consideração individualizada. Dedica atenção } \\
\text { especial, trata cada funcionário individualmente, } \\
\text { orienta tecnicamente, aconselha. }\end{array}$ \\
\hline
\end{tabular}

Quadro 4 - Características dos Líderes Transacionais e Transformacionais

Fonte: Robbins ( 2001, p. 397)

\subsubsection{Liderança Visionária}

Segundo Rowe (2002), a liderança visionária é o estilo mais difícil de se avaliar, considerando-se que a sua escala de performance é muito variável. Esses líderes buscam criatividade, inovação, desordem e muitas mudanças nas organizações provocando instabilidade nas mesmas, conseqüentemente a falta de apoio com estrutura, controle e recompensas adequadas.

Para Rowe (2002), apesar de alguns estudiosos considerarem o estilo visionário e de liderança gerencial distintos, entendem que ambos são essenciais para a viabilidade em longo prazo e a estabilidade financeira a curto prazo na organização. Assinalam que, quando a liderança visionária é bem exercida dificilmente é copiada, tornando o seu grau de importância muito mais significativo.

\subsection{Relacionamento, Tarefa e Situação: integrando estilos gerenciais}

Para Melo (2001), as diferentes abordagens sobre liderança não são excludentes, pelo contrário, elas podem ser consideradas de forma complementar. Assim, assegura o autor, o fenômeno da liderança seria uma função das características dos líderes, dos comportamentos por eles apresentados e também de condições situacionais. 
Com base nesse pressuposto, Melo (2001) construiu e validou a Escala de Avaliação dos Estilos Gerenciais (EAEG), para avaliar três estilos gerenciais muito citados na literatura sobre liderança: o estilo voltado para o Relacionamento; o estilo voltado para a Tarefa e o estilo voltado para a Situação.

Segundo Melo, é possível observar, de acordo com as diferentes abordagens de liderança, que a atuação dos gerentes se volta sempre para um desses três focos Relacionamento, Tarefa e Situação, conforme ilustra o Quadro 5:

\begin{tabular}{|c|c|}
\hline Foco & Abordagem \\
\hline 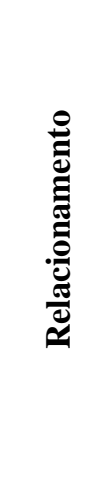 & 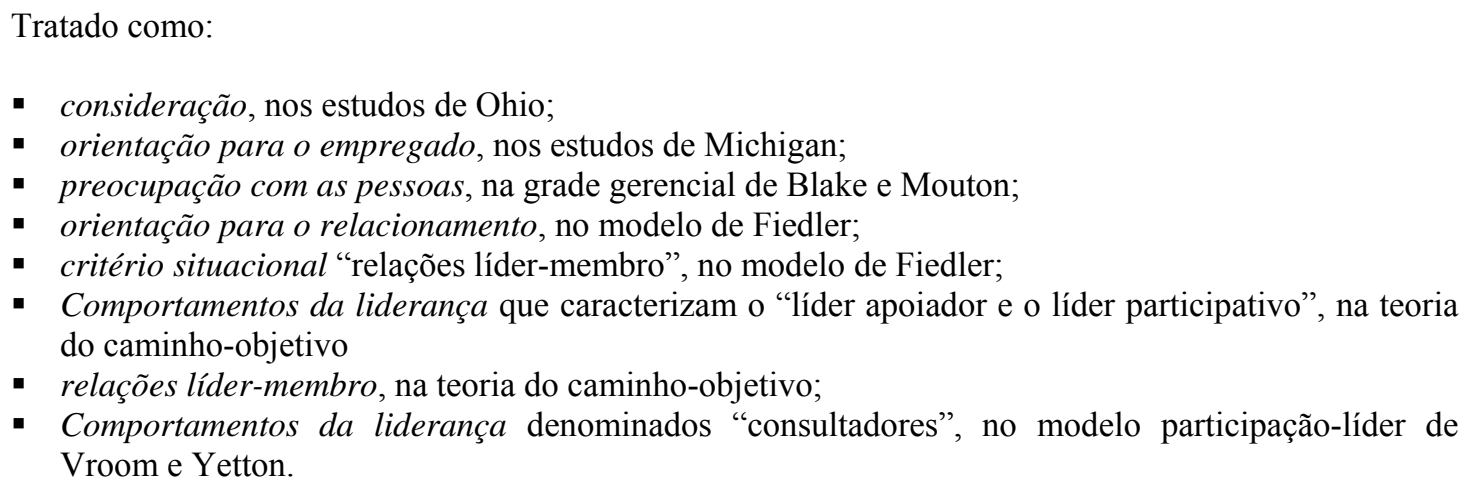 \\
\hline 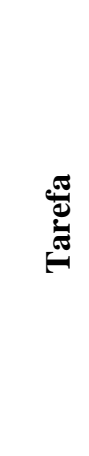 & 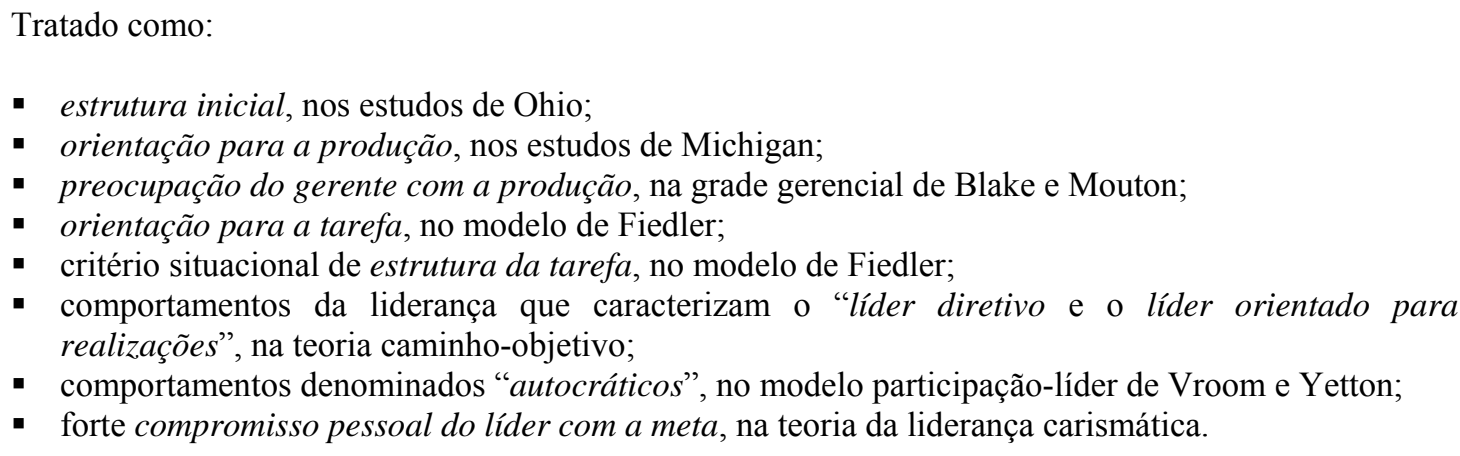 \\
\hline 龸 & $\begin{array}{l}\text { Tratado como: } \\
\text { - Todas as teorias contingenciais destacam a dimensão situacional. }\end{array}$ \\
\hline
\end{tabular}

Quadro 5 - Estilos Gerenciais e Abordagens Teóricas de Liderança

Fonte: Melo (2001)

A partir da análise dos pontos convergentes de cada abordagem teórica de liderança, Melo (2001) elaborou a definição constitutiva para cada um dos três estilos gerenciais que buscou incorporar na construção da EAEG: 
- Relacionamento - Refere-se à extensão em que o líder terá relações de trabalho que sejam caracterizadas por confiança mútua, amizade, calor humano nas relações, respeito pelas idéias dos subordinados e interesses por seus sentimentos. O líder valoriza a individualidade e enfatiza as relações interpessoais tais como apoio, orientação e facilitação.

- Tarefa - Refere-se à probabilidade que o líder tem para definir e estruturar o seu papel e o dos subordinados na busca da realização de metas. O líder enfatiza o trabalho, os aspectos técnicos da função, a observância aos padrões, os canais de comunicação, os procedimentos e os métodos, bem como a realização das tarefas.

- Situação - Refere-se à habilidade do gerente para identificar a realidade do seu ambiente de trabalho e de adaptar o seu estilo às exigências desse ambiente. $\mathrm{O}$ líder é flexível para variar o seu comportamento de acordo com as necessidades e motivos dos seus subordinados.

\subsection{Função Gerencial}

Motta (1996) considera que a revisão dos conceitos baseados nos desafios competitivos da gerência japonesa na década de 1990, foi muito relevante para a prática da gestão. Para Motta (1996), as palavras administração, gerência e gestão têm o mesmo significado. Neste contexto, será utilizada a "gerência" por estar sendo tratada no presente item.

De acordo com Motta (1996) gerência significa função subordinada aos conselhos superiores, onde os gerentes ou executivos encarregavam-se de executar a ordem dos diretores, proprietários ou membros do conselho de administração e empresas. No Brasil, o uso indiscriminado das expressões de administração e gerentes colaborou para que fosse adotado para qualquer posição de direção e chefia, tornando-se sinônimo de insatisfação, inutilidade e de pessimismo favorecendo a criação de novos conceitos.

Conforme Motta (1996) o uso da gerência prevaleceu sendo utilizada nas funções executivas com total aceitação apesar de várias pesquisas e estudos ainda permanecerem ambíguas com outras funções técnicas e administrativas, oriundas da visão ordenada e tradicional da própria função, quanto dos contextos organizacionais.

Segundo Motta (1996) as pesquisas demonstram que os gerentes são pessoas dedicadas à função, tomam decisões baseadas em informações parciais e imprecisas e 
manifestam ações e opiniões isoladas e incoerentes. Apesar do resultado do seu trabalho ser avaliado a longo prazo, são pressionados a darem respostas em um curto espaço de tempo.

Para Motta (1996), durante um longo período idealizou-se que a combinação da função gerencial e organização do trabalho, poderiam ser desenvolvidas por um dirigente com eficácia nos objetivos da empresa, com capacidade de comando e coordenação de trabalho coletivo. Posteriormente verificou que os gerentes possuíam bastante compreensão sobre os objetivos da organização e estavam aptos a alcançá-los.

Entretanto Motta (1996) observou que os gerentes tinham dificuldade com o processo decisório organizacional, o que influenciava o seu comportamento administrativo tornando suas atitudes algumas vezes ilógicas. O processo decisório organizacional é um dos fatores fundamentais do comportamento gerencial que antecede e determina a própria decisão.

Motta (1996) observa que na maioria das vezes, os gerentes não têm visão clara nem ciência dos problemas funcionais quando assumem a sua primeira função. Para suprirem as suas deficiências, costumam minimizar as dificuldades através do conhecimento sistêmico, objetivando justificar, defender possíveis mudanças e encobrirem os seus desconhecimentos e habilidades gerenciais. Cabe ao gerente, além de coordenar e organizar a mão-de-obra, induzir os valores da organização com o propósito de reduzir os conflitos existentes entre o interesse pessoal e organizacional.

Para Motta (1996) para que a gerência seja eficazmente desempenhada, é primordial a existência de habilidade do gerente para pensar, julgar, decidir e agir coerentemente, fazer acontecer, obter resultados, antecipar as ações de forma eficiente, ter capacidade analítica para analisar as diferentes fases, dar soluções e enfrentar riscos e incertezas.

De acordo com Motta (1996), o aprendizado gerencial deve estar atrelado aos ensinamentos do indivíduo, advindos de sua experiência individual interna e externa à organização agregados aos novos conhecimentos, cultura organizacional, capacidade de percepção para análise de problemas, de alternativas comportamentais, estilos gerenciais e ações mais eficientes e eficazes.

O Quadro 6, apresentado a seguir, mostra as quatro dimensões básicas de habilidades desenvolvidas no aprendizado organizacional: 


\begin{tabular}{|c|c|c|}
\hline Tipo de habilidade & Significado & Objetivo \\
\hline Cognitiva & $\begin{array}{l}\text { Saber categorizar } r \\
\text { administrativos e ver } \\
\text { categorias. }\end{array}$ & $\begin{array}{l}\text { Aprender sobre administração a partir do } \\
\text { estoque de conhecimentos existentes sobre } \\
\text { definição de objetivos e formulação de } \\
\text { políticas e de idéias sistematizadas sobre } \\
\text { estruturas, processos, técnicas e } \\
\text { comportamentos organizacionais. }\end{array}$ \\
\hline Analítica & $\begin{array}{l}\text { Saber a utilidade e a potencialidade das } \\
\text { técnicas administrativas e adquirir mais } \\
\text { realismo, profundidade e criatividade na } \\
\text { solução de problemas. }\end{array}$ & $\begin{array}{l}\text { Aprender a decompor problemas } \\
\text { administrativos, identificar variáveis } \\
\text { fundamentais, estabelecer relações de causa } \\
\text { e efeito na busca de novas soluções, } \\
\text { objetivos, prioridades e alternativas de ação. }\end{array}$ \\
\hline Comportamental & $\begin{array}{l}\text { Comportar-se de forma diferente do } \\
\text { anteriormente acostumado para obter } \\
\text { respostas comportamentais mais } \\
\text { consistentes com objetivos de eficiência, } \\
\text { eficácia, satisfação e segurança no } \\
\text { trabalho. }\end{array}$ & $\begin{array}{l}\text { Aprender novas maneiras de interação } \\
\text { humana dentre padrões alternativos } \\
\text { conhecidos e validados socialmente, como } \\
\text { novas formas de comunicação de interação } \\
\text { grupal ou de exercer ou lidar com poder e } \\
\text { autoridade. }\end{array}$ \\
\hline De ação & $\begin{array}{l}\text { Desenvolver capacidade de interferir } \\
\text { intencionalmente no sistema } \\
\text { organizacional, ou seja, de trans formar } \\
\text { objetivos, valores e conhecimentos em } \\
\text { formas efetivas de ação. }\end{array}$ & $\begin{array}{l}\text { Aprender sobre si próprio, sobre sua função } \\
\text { e sobre os objetivos e condições } \\
\text { operacionais de sua organização. } \\
\text { Desenvolver comprometimento com a } \\
\text { missão sócio-econômica da instituição em } \\
\text { que trabalha. }\end{array}$ \\
\hline
\end{tabular}

Quadro 6 - Significados e Objetivos de Habilidades Gerenciais Fonte: Adaptado de Motta (1996, p. 29)

De acordo com Motta (1996) nas empresas contemporâneas, os profissionais têm que ter capacidade e habilidade altamente desenvolvidas para responderem as demandas de negociação, julgamento, decisão, liderança, de sobreviverem aos riscos e incertezas, bem como serem autoconfiantes na obtenção de êxito futuro visando contribuir para o reconhecimento profissional.

Conforme Motta (1996), os profissionais que utilizam apenas o bom-senso e experiências passadas, não são mais necessários nessas empresas. Salienta que algumas habilidades gerenciais são conquistadas no dia-a-dia através das suas contradições, mudanças e sistematizações, sendo a última, largamente ensinada e utilizada pelos profissionais que se dedicam à gerência. 
Almeida e Sobral (2005) identificam o modelo de gestor negociador como uma função fundamental na atividade organizacional em que o êxito da competência gerencial relacionase ao processo gerencial. Observam que as características pessoais são desprezadas à medida que contribuem ou não para a obtenção de um bom resultado na negociação. Esses autores consideram o fator emocional como primordial no processo de negociação, uma vez que evidenciam alguns sentimentos e o impacto dos mesmos no processo. Ressaltam que a emoção também pode ser premeditada e utilizada como ferramenta para a transmissão de mensagens falsas e descumprimento de acordos e que os gestores com maior grau de inteligência cognitiva oferecem mais alternativas para a resolução de problemas com papéis determinantes na solução de conflitos.

No Quadro 7, apresentado a seguir, são comparados os mitos (perspectiva ordenada, lógica e racional da função) e as verdades (realidade do trabalho gerencial, uma visão mais ordenada e fragmentada da função), distorções observadas pelos gerentes e outros profissionais no trabalho diário da organização, de acordo com Motta (1996): 


\begin{tabular}{|c|c|}
\hline Mitos & Verdades \\
\hline $\begin{array}{l}\text { 1. Pessoa com status, autoridade e poder tem sala } \\
\text { imponente em andar elevado. Toma decisões rápidas, } \\
\text { analisa informações e supera obstáculos, confiante e } \\
\text { segura no sucesso das decisões (imagens de "super- } \\
\text { homem"). }\end{array}$ & $\begin{array}{l}\text { 1. Pessoa com status às vezes duvidoso; poder e } \\
\text { autoridade dependente de injunções contínua e de } \\
\text { informações obtidas de várias maneiras. Negocia } \\
\text { assuntos diversos, ganhando e perdendo, tenso, } \\
\text { nervoso e incerto quanto ao resultado das decisões. }\end{array}$ \\
\hline $\begin{array}{l}\text { 2. Atuação baseada em ações ordenadas e planejadas } \\
\text { num processo decisório acentuadamente racional e } \\
\text { impessoal. }\end{array}$ & $\begin{array}{l}\text { 2. Atuação baseada em ações desordenadas e } \\
\text { intermitentes num processo decisório marcado } \\
\text { também por decisões intuitivas e influenciadas por } \\
\text { lealdades pessoais e comunicações verbais face a face. }\end{array}$ \\
\hline $\begin{array}{l}\text { 3. Preocupação prioritária com políticas, diretrizes e } \\
\text { desenvolvimento, futuro da organização. }\end{array}$ & $\begin{array}{l}\text { 3. Preocupação prioritária com operações atuais e } \\
\text { solução de problemas prementes. }\end{array}$ \\
\hline $\begin{array}{l}\text { 4. Trabalho programado, com algumas fases } \\
\text { previsíveis e problemas antecipados para enfrentar } \\
\text { contingências e superar dificuldades. }\end{array}$ & $\begin{array}{l}\text { 4. Trabalho não-programado, em grande } \\
\text { imprevisível. Enfrentamento constante } \\
\text { contingências e de problemas desconhecidos. }\end{array}$ \\
\hline $\begin{array}{l}\text { 5. Instrumentos de trabalho: objetivos, programas, } \\
\text { metas, resultados e prazos. }\end{array}$ & $\begin{array}{l}\text { 5. Instrumentos de trabalho: surpresas, sustos, } \\
\text { contingências e problemas. }\end{array}$ \\
\hline 6. Reúne-se para planejar e discutir. & $\begin{array}{l}\text { 6. Reúne-se para discutir as dificuldades das rotinas e } \\
\text { debater temas na presunção de que poderá haver } \\
\text { problemas. }\end{array}$ \\
\hline $\begin{array}{l}\text { 7. Recebe informações fundamentais para a decisão } \\
\text { através de relatórios de assessores, memorandos } \\
\text { internos, impressos de computadores e informações } \\
\text { orais em reuniões programadas. }\end{array}$ & $\begin{array}{l}\text { 7. Recebe informações fundamentais através de um } \\
\text { excessivo e variado número de contatos pessoais, por } \\
\text { comunicação verbal, telefonemas, bate-papos } \\
\text { informais e em reuniões de última hora. }\end{array}$ \\
\hline 8. Comportamento formal e contemplativo. & 8. Comportamento informal e interativo. \\
\hline $\begin{array}{l}\text { 9.Trabalha com sistematização, afinco e profundidade } \\
\text { em um número reduzido de tarefas e informações mais } \\
\text { importantes para a tomada de decisão. }\end{array}$ & $\begin{array}{l}\text { 9.Trabalha sem sistematização, de forma superficial e } \\
\text { intermitente em um grande número de tarefas, } \\
\text { exercendo funções diferentes no que se refere a cada } \\
\text { tarefa. }\end{array}$ \\
\hline $\begin{array}{l}\text { 10. Trabalho prospectivo, de médio e longo prazo, } \\
\text { orientado para soluções e integrado com as diversas } \\
\text { áreas de organização. }\end{array}$ & $\begin{array}{l}\text { 10. Trabalho restritivo, de curto prazo, orientado a } \\
\text { problemas e fragmentado no que se refere às diversas } \\
\text { áreas de organização. }\end{array}$ \\
\hline
\end{tabular}

Quadro 7 - Mitos e verdades sobre as funções do dirigente

Fonte: Adaptado de Motta (1996, p. 24-25)

O Quadro 8, apresentado a seguir, mostra os mitos sobre qualidades para o exercício gerencial: 


\begin{tabular}{|c|c|c|c|}
\hline Qualidades & $\begin{array}{l}\text { Mitos sobre a } \\
\text { suficiência }\end{array}$ & $\begin{array}{l}\text { Padrões de } \\
\text { recrutamento } \\
\text { recorrentes } \\
\end{array}$ & Realidades sobre a insuficiência \\
\hline Bom senso & $\begin{array}{l}\text { O bom senso é a } \\
\text { qualidade central do } \\
\text { gerente. A visão do } \\
\text { senso comum e a } \\
\text { experiência são } \\
\text { suficientes para a } \\
\text { administração eficiente } \\
\text { de uma organização. } \\
\end{array}$ & $\begin{array}{l}\text { Pessoas razoáveis, } \\
\text { incapazes de riscos } \\
\text { indevidos e com } \\
\text { grande experiência de } \\
\text { trabalho. }\end{array}$ & $\begin{array}{l}\text { Bom senso e experiência são } \\
\text { requisitos para todas as funções } \\
\text { importantes. A complexidade dos } \\
\text { sistemas organizacionais modernos } \\
\text { exige habilidades gerenciais que } \\
\text { ultrapassam em muito as que podem } \\
\text { ser aprendidas pelo bom senso e } \\
\text { experiência. }\end{array}$ \\
\hline Autoridade do cargo & $\begin{array}{l}\text { A autoridade do cargo é } \\
\text { fonte de legitimidade e } \\
\text { poder suficiente para } \\
\text { influenciar pessoas e } \\
\text { obter os } \\
\text { comportamentos } \\
\text { administrativos } \\
\text { desejáveis. }\end{array}$ & $\begin{array}{l}\text { Pessoas hábeis no uso } \\
\text { do poder e da } \\
\text { autoridade e com } \\
\text { visão de mando. }\end{array}$ & $\begin{array}{l}\text { O comportamento administrativo de } \\
\text { um indivíduo é produto de um } \\
\text { conjunto de fatores internos e } \\
\text { externos ao seu meio de trabalho, } \\
\text { grande parte deles incontrolável pela } \\
\text { autoridade hierárquica. }\end{array}$ \\
\hline $\begin{array}{l}\text { Qualidade de } \\
\text { decisão }\end{array}$ & $\begin{array}{l}\text { A qualidade técnica da } \\
\text { decisão política é a base } \\
\text { principal para obtenção } \\
\text { de consenso e para } \\
\text { resposta adequada do } \\
\text { meio organizacional. } \\
\text { Implementação } \\
\text { eficiente é a } \\
\text { decorrência técnica e } \\
\text { natural da boa decisão } \\
\text { política. }\end{array}$ & $\begin{array}{l}\text { Profissionais } \\
\text { capacitados e de } \\
\text { competência } \\
\text { comprovada no } \\
\text { exercício de funções } \\
\text { técnicas, típicas da } \\
\text { organização que } \\
\text { pretende dirigir. }\end{array}$ & $\begin{array}{l}\text { A implementação é um processo da } \\
\text { mesma natureza e passível das } \\
\text { mesmas influências técnicas e } \\
\text { políticas que a formulação de } \\
\text { diretrizes. Capacidade técnica do } \\
\text { dirigente é importante, ma a } \\
\text { qualidade da decisão não garante } \\
\text { implementação suficiente. }\end{array}$ \\
\hline $\begin{array}{l}\text { Conhecimento de } \\
\text { procedimentos } \\
\text { burocráticos }\end{array}$ & $\begin{array}{l}\text { O conhecimento da } \\
\text { "máquina } \\
\text { administrativa", ou seja, } \\
\text { o domínio dos } \\
\text { procedimentos } \\
\text { administrativos } \\
\text { normalmente usados em } \\
\text { uma organização, é } \\
\text { suficiente para alcançar } \\
\text { os resultados desejados. }\end{array}$ & $\begin{array}{l}\text { Pessoas experientes } \\
\text { no exercício das } \\
\text { funções burocráticas } \\
\text { e conhecedoras de } \\
\text { leis, normas e } \\
\text { procedimentos } \\
\text { administrativos } \\
\text { pertinentes. }\end{array}$ & $\begin{array}{l}\text { O conhecimento de procedimentos } \\
\text { burocráticos é uma ajuda para a ação } \\
\text { suficiente no status quo } \\
\text { administrativo, mas pouco tem a ver } \\
\text { com a capacidade dee inovação que } \\
\text { constituem as habilidades gerenciais } \\
\text { modernas. }\end{array}$ \\
\hline
\end{tabular}

Quadro 8 - Mitos sobre qualidades para o exercício gerencial

Fonte:Adaptado de Motta (1996, p. 33-34)

Para Motta (1996), as organizações contemporâneas diante das complexidades apresentadas, também sofreram mudanças nas formas clássicas da gestão: de rígidas e precisas para ambíguas e flexíveis, oportunizando novidades tais como:

- Transações ambientais: contatos externos e estratégico com o público, clientes e outras instituições não são mais concentrados na alta hierarquia, os contatos passam a ocorrer em todos os níveis hierárquicos. 
- Participação no processo decisório organizacional: Antes concentrada nos dirigentes e técnicos, atualmente envolve funcionários de nível hierárquico mais baixo, com pessoal de apoio além dos grupos internos e externos.

- As estruturas organizacionais que favoreciam a tomada de decisão estratégica de forma centralizada, passam a sofrer pressões acentuadas para a descentralização, modulação e redução de quadro.

- Informações antes tratadas de forma cautelosa, restrita e até mesmo confidencial passam a ser divulgadas amplamente, tornando-se acessível a todos.

Como conseqüência das mudanças em que se tornam mais complexas para a gerência de alto nível, os gerentes de nível intermediário e local vêem necessidade de adquirir o mesmo conhecimento dos gerentes de alto nível.

Hoje em dia, as grandes organizações mostram discrepância quanto ao trabalho gerencial sob a ótica clássica que fundamentava a gerência por níveis hierárquicos, conforme sintetiza Motta (1996) no Quadro 9:

\begin{tabular}{|c|c|c|}
\hline Nível & Perspectiva clássica & Realidade contemporânea \\
\hline Alto nível & $\begin{array}{l}\text { Dirigentes trabalham na formulação de } \\
\text { políticas e estratégias, pensando no } \\
\text { futuro da organização e desenvolvendo } \\
\text { alternativas de longo prazo. Procuram } \\
\text { exercer a liderança e estabelecer as } \\
\text { relações externas fundamentais. }\end{array}$ & $\begin{array}{l}\text { Dirigentes trabalham na solução de problemas } \\
\text { urgentes e de curto-prazo, numa função } \\
\text { fragmentada por reuniões e contatos externos e } \\
\text { internos. Se desapontam pela pouca } \\
\text { disponibilidade para planejar e pensar no futuro e } \\
\text { pelas dificuldades burocráticas para o exercício da } \\
\text { liderança. }\end{array}$ \\
\hline $\begin{array}{c}\text { Nível } \\
\text { intermediário }\end{array}$ & $\begin{array}{l}\text { Gerentes de nível intermediário tratam } \\
\text { dos meios necessários para atingir os } \\
\text { objetivos estratégicos. Trabalham em } \\
\text { operações táticas de curto prazo e } \\
\text { menor escopo, dentro dos limites } \\
\text { estratégicos fixados pelos níveis } \\
\text { superiores. }\end{array}$ & $\begin{array}{l}\text { Trabalham no desenho de projeto e planos futuros } \\
\text { em meio a pressões de cima e de baixo para } \\
\text { solução de problemas imediatos e se desapontam } \\
\text { pela pouca atenção superior a suas idéias de futuro } \\
\text { e pelas inabilidades constantes de subordinados } \\
\text { em resolver questões rotineiras. (Função em } \\
\begin{array}{l}\text { decadência/extinção } \\
\text { descentralização) }\end{array}\end{array}$ \\
\hline $\begin{array}{l}\text { Nível de } \\
\text { supervisão }\end{array}$ & $\begin{array}{l}\text { Supervisores gerenciam processos } \\
\text { técnicos e rotineiros necessários à } \\
\text { conclusão de tarefas específicas. } \\
\text { Trabalham com escopo e prazo restritos } \\
\text { e fixados nos níveis intermediários. }\end{array}$ & $\begin{array}{l}\text { Trabalham em propostas de solução e questões } \\
\text { estratégicas pressionados por clientelas e } \\
\text { subordinados para serem levados à alta direção. } \\
\text { Adquirem informações em grau e natureza quase } \\
\text { semelhantes a níveis superiores. (Função de } \\
\text { importância crescente devido a descentralização). }\end{array}$ \\
\hline
\end{tabular}

Quadro 9 - Divergências entre as perspectivas clássicas e modernas das funções gerenciais.

Fonte: Adaptado de Motta (1996, p. 36) 


\subsection{Pesquisas Nacionais sobre Liderança}

Esta seção apresenta os resultados de alguns trabalhos de pesquisa nacionais sobre liderança apresentados no $30^{\circ}$ e $31^{\circ}$ Encontro Nacional da ANPAD (EnANPAD), realizados nos anos de 2006 e 2007, respectivamente. Uma síntese dessas pesquisas será apresentada a seguir:

Cabral, Rocha e Semiotti (2007) desenvolveram uma pesquisa através de questionários e grupo de discussão em uma empresa do qual participaram 03 diretores da alta administração, 15 gerentes administrativos, 32 superintendentes e líderes de equipe operacionais para identificar as emoções dos líderes no desenvolvimento de suas competências de liderança. Os autores (2007) observaram que os gestores desconhecem o papel de líderes, confundem a função de gestor e liderança e que as responsabilidades e competências necessitam serem mais trabalhadas. Também identificaram a concentração das ações nos aspectos operacionais com o controle das tarefas em detrimento da gestão de pessoas, com acentuada dificuldade para definir responsabilidades e limites de autonomia. Através da aferição das médias de competência abaixo, constatou-se que:

- Competência 1: Compreensão interpessoal (4,58\%)

- Competência 2: Confronto de membros que rompem as normas $(4,19 \%)$

- Competência 3: Comportamento atencioso $(4,71 \%)$

- Competência 4: Auto-avaliação da equipe (4,31\%)

- Competência 5: Criação de recursos para trabalhar com emoção $(3,88 \%)(\downarrow)$

- Competência 6: Criação de um ambiente afirmativo (4,61\%)

- Competência 7: Solução pro-ativa de problemas (4,31\%)

- Competência 8: Compreensão organizacional

- Competência 9: Criação de relações externas $(4,88 \%)(\uparrow)$

O resultado obtido na competência de $\mathrm{n}^{0} 5$ aponta que os gestores precisam desenvolver estratégias individuais e coletivas para sanarem as suas insensibilidades tais como: autoconsciência emocional, empatia e gerenciamento de conflitos que visem aquisição de habilidades objetivando a obtenção de respeito as emoções expressadas no dia-a-dia, com o intuito de estimular a comunicação entre as pessoas.

A competência $n^{\circ} 9$ indica que a ocorrência de laços de amizade entre líderes e liderados, algumas vezes contribui para o comprometimento do vínculo profissional. Em alguns casos, esse vínculo favorece o liderado, uma vez que, passa a não receber advertência e 
feedback do chefe. Geralmente, os gestores tornam-se mais complacentes com o subordinado/amigo confundindo os laços pessoais e profissionais.

Cabral, Rocha e Semiotti (2007) concluem ser importante que os líderes invistam no seu campo emocional para que haja total interação com a vida profissional. O resultado da pesquisa demonstrou que os gestores devem desenvolver estratégias de ajuda mútua para a demanda diária e aprenderem competências sobre liderança.

Silva, Laros e Mourão (2007) conduziram uma pesquisa em uma instituição pública federal de Brasília em 2004, sobre a atuação gerencial na ótica dos gerentes e subordinados. Foram distribuídos questionários para 451 gerentes e 1590 subordinados. Os autores (2007) desenvolveram uma escala, segundo a técnica Delphi, para demonstrar que: a) os gerentes são menos rigorosos em sua auto-avaliação; b) não são receptivos aos feedbacks contrários as suas opiniões; c) apresentam maior uniformidade na avaliação dos subordinados; d) apresentam uma grande dificuldade de comunicação com os subordinados para relatos de ocorrências de outras áreas; e) não são hábeis para motivação de equipe.

Silva, Laros e Mourão (2007) observaram que os gerentes manifestam opiniões distintas relativas a questionamentos de outros gerentes, apóiam a aplicação de novos conhecimentos e habilidades no trabalho, distribuem tarefas de acordo com o perfil de cada membro e consideram a opinião da equipe no momento de tomada de decisões. O resultado da pesquisa evidenciou que o papel desempenhado nas atividades dos líderes gerencial é primordial para um eficiente funcionamento das relações no trabalho, considerando que as influências exercidas sobre os funcionários ajudam a desenvolver eficientes processos de trabalho executados pelos seus liderados para a realização de metas previamente definidas.

Schimitt e Leal (2006) realizaram pesquisa no período de 2002 e 2003 em duas empresas multinacionais, sendo a primeira Empresa Alfa, do setor metalúrgico e a última não identificada do setor de desenvolvimento estratégico. A pesquisa conduzida pelos autores (2006), objetivava identificar a figura do líder e mito como processo para a prática de afetividade. Os autores (2006) observaram na Empresa Alfa a existência de uma forte ligação com a figura do mito-fundador, tendo em vista que os valores como responsabilidade, transparência, confiança, imparcialidade, determinação, credibilidade, legalidade e diversidade cultural propostas pelo seu fundador ainda são amplamente utilizados, enfatizados nos manuais e reproduzidos pessoalmente pelos dirigentes da organização.

De acordo com Schimitt e Leal (2006) tais atitudes evidenciam os mesmos valores propostos pelo seu fundador relativos a: respeito, caridade e sentimento de irmandade que reproduz para o funcionário o bem- estar de todos. A segunda pesquisa mostrou que o êxito da 
liderança diretor-presidente, foi resultado da forma de tratamento dispensada aos seus colaboradores, tendo como foco principal do modelo de gestão o mérito, a simplicidade, a obsessão por reduzir gastos, os processos e entusiasmo. Para os pesquisadores (2006), a identificação do individuo com a organização é pertinente com a visão da mesma como um objeto para a realização dos seus desejos e anseios. Consideram que a fragilidade do mercado contribui para aumentar a auto-estima através da admiração pelo seu superior, que utiliza desse desejo para desenvolver o controle psicológico de desempenho no indivíduo, tornandoo um fator importante na prática gerencial possibilitando alcançar todos os seus objetivos com os seus liderados.

Siqueira (2006) denomina essa prática como controle do amor, isto é, mecanismo em que o trabalho torna-se fonte de prazer do indivíduo que valoriza a empresa, tornando-a o fator mais importante da sua vida, associado a estratégia de sedução. O resultado da pesquisa demonstrou que o modelo de liderança utilizado em ambas as empresas são representados pelo controle de afeto, enfatizando que o mesmo é utilizado para responder aos desejos mais íntimos, como forma de impedir críticas ao modelo de gestão utilizado. As duas figuras mito e líder representam o alto índice de desempenho, conduta, carisma e valores morais.

Carvalho e Medeiros (2006) realizaram um estudo no SERPRO com 60 gerentes de nível médio distribuídos em Brasília e todas as regionais do Brasil no período de 2000 à 2002 . A abrangência nacional justifica-se tendo em vista que todos os gerentes entrevistados fazem elo de ligação entre a alta gerência e a operacionalização, facilitando a conversão dos diferentes modos de conhecimento e agregando-o as novas tecnologias, produtos e serviços. O objetivo de estudo foi identificar os aspectos de liderança que possibilitam a criação de conhecimento e como o líder é capaz de influenciar os liderados para que se motivem a criarem novos conhecimentos na organização.

Carvalho e Medeiros (2006) utilizaram a experiência japonesa geradora da Teoria da Criação do Conhecimento, para justificar a abordagem explicita (formal e sistemático) dos gerentes ocidentais, composto pela teoria e prática passiveis de serem compartilhadas sob a forma de dados e informação, em palavras e números de maneira formalizada. Na conclusão da pesquisa, os autores (2006) enfatizam a relevância da participação de todos os indivíduos da organização para a criação do conhecimento organizacional e constatam que de todos os fatores de liderança como: Solicitude, Poder, Habilidades Humanas, Pessoas e Tarefas, o fator Solicitude foi o que mais se destacou com $(86,7 \%)$ para a criação do conhecimento cujas dimensões são: 
- Confiança mútua: Espera-se que as opinião do empregado sobre o chefe seja usada por ambos da melhor maneira possível;

- Leniência nos julgamentos: Considerar os antecedentes, estado psicológico do empregado no momento da incompetência do mesmo;

- Empatia ativa: Tentar colocar-se no lugar do empregado para compreender os seus interesses, habilidades, sucessos, fracassos, oportunidades e problemas;

- Disposição para ajuda: Estar disponível aos empregados para transferir habilidades e aprendizado, e

- Coragem: Admitir críticas, submeter-se a julgamento e dar feedback.

Cochia, Caetano Júnior e Borges (2007) realizaram um estudo em 2004 utilizando o modelo de liderança criativa em uma concessionária de motocicletas no Paraná com distribuição de questionário para 112 funcionários distribuídos em 03 cidades do estado. $\mathrm{O}$ estudo visava abordar o aspecto da liderança sob a ótica da inovação e criatividade nas organizações. Esse estilo de liderança é participativo e apoiador com ênfase na ajuda mútua e cooperação como um processo de influência compartilhada sem a presença formal de um líder.

De acordo com Cochia, Caetano Júnior e Borges (2007) a pesquisa se baseou no modelo empírico desenvolvido a partir de consultoria em mais de 2.000 equipes de trabalho, em inúmeras organizações, para observar o comportamento dos líderes e liderados em atividades de desenvolvimento de novos produtos e serviços e o aumento da criatividade e inovação das equipes de trabalho. Os autores (2007) utilizaram os sete fatores do modelo de liderança criativa de Richardson e Moger 1990 e 2000, fundamentado em equipes de trabalho com os mesmos objetivos que resultem em produtos e serviços. Os fatores apresentados resultam da ação do líder e sua relação com a equipe. Os sete saberes são:

- Plataforma do entendimento: O líder desde o início do processo estimula os liderados a dividirem os seus conhecimentos, bem como estabelecerem os seus papéis dentro do trabalho a ser desenvolvido.

- Visão compartilhada: Criada a partir do acesso da plataforma de entendimento. Identifica idéias dos membros da equipe dando visibilidade a relação de poder.

- Clima: Objetiva propiciar o compartilhamento, confiança e a abordagem positiva e Apoiadora. 
- Resiliência: Flexibilidade para administrar as barreiras e desapontamentos, oportunizando aos líderes e todos os membros a buscarem alternativas para suprirem as dificuldades encontradas.

- Idéias próprias: Comprometimento com as próprias idéias e responsabilidade para colocá-las em prática. Os líderes geralmente alinham as idéias da equipe em áreas onde os membros têm total domínio e controle.

- Ativação em rede: Equipes de trabalho altamente criativas possuem contatos externos, utilizam a rede para troca de informação, auxílio técnico e fornecimento de recursos para cumprirem os seus objetivos na organização;

- Aprendizado vindo da experiência: Os membros compartilham as suas próprias experiências de crescimento com os colegas, estimulados pelo líder.

A pesquisa concluiu que, a liderança transformacional associada a liderança criativa utilizada pelo líder para identificar motivações é predominante na empresa. Esse tipo de liderança estimula o engajamento e comprometimento das pessoas na obtenção dos objetivos. 


\section{CAPÍTULO 2 - METODOLOGIA DA PESQUISA}

\subsection{Tipo de Pesquisa}

Segundo Vergara (2005), na literatura podem ser encontrados inúmeros tipos de pesquisa que se agreguem aos critérios utilizados pelos estudiosos no assunto. No presente estudo, foram utilizados os critérios básicos propostos pôr Vergara (2005), que classifica os tipos de pesquisa quanto aos fins a que se destina, a pesquisa realizada foi do tipo descritiva e aplicada. Descritiva porque expõe características de determinada população ou de determinado fenômeno. Aplicada porque é motivada pela necessidade de resolver problemas reais, portanto, com finalidade prática.

Quanto aos meios de investigação foi bibliográfica e de campo. Bibliográfica porque para embasar a fundamentação teórico-metodológica do trabalho foram utilizados todos os suportes bibliográficos que contribuíssem para enriquecer o assunto, tais como: livros, dissertações, revistas e meios eletrônicos. A pesquisa foi também de campo, por ter sido aplicado um questionário para a coleta de dados a todos os sujeitos da pesquisa.

\subsection{Contexto da Pesquisa}

A pesquisa foi desenvolvida na Biblioteca Central da Universidade de Brasília (UnB), instituição pública de ensino superior inaugurada em 1962, com a missão de produzir, integrar e divulgar conhecimento para formar cidadãos comprometidos com a ética, a responsabilidade social e o desenvolvimento sustentável.

Segundo narra Marcelino (2004) a UnB começou com cursos organizados em três troncos básicos de estudos: Direito, Administração e Economia, Letras Brasileiras, Arquitetura e Urbanismo. A estrutura administrativa da Instituição está constituída nos três pilares fundamentais: gestão democrática, descentralização e racionalidade acadêmica.

Atualmente, a UnB possui dois campi, um em Brasília e outro na cidade satélite de Planaltina, além dos órgãos complementares que são o Hospital Universitário, a Fazenda Águas Limpas e a Editora que agregam valores aos trabalhos de ensino, pesquisa e extensão.

Informações coletadas no dia 08 de abril de 2008, no site institucional da UnB, apontam que a universidade possui cerca de 22.370 alunos de graduação distribuídos em 63 cursos; 2.963 alunos de mestrado distribuídos em 64 cursos, 1.634 alunos de doutorado distribuídos em 45 cursos e dezenas de cursos de especialização. 
A Biblioteca Central (BCE), unidade onde foi desenvolvida a pesquisa, faz parte da estrutura administrativa da UnB e teve seu funcionamento iniciado em 1962, juntamente com a oferta dos primeiros cursos. Possui, atualmente, um arquivo de mais de um milhão e trezentos mil livros. A BCE funciona todos os dias da semana, o que a diferencia de outras bibliotecas brasileiras.

A Figura 3 apresenta o organograma da BCE:

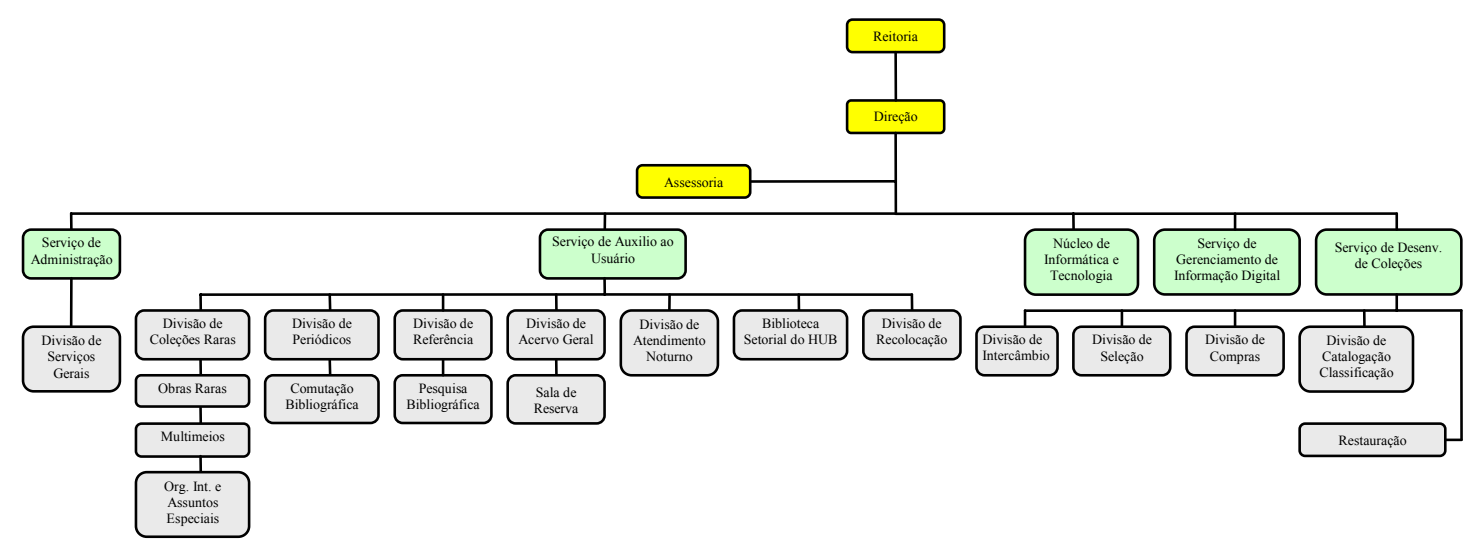

Figura 3 - Organograma da Biblioteca Central da UnB

Fonte: $\mathrm{UnB} / \mathrm{BCE}$ 


\subsection{Participantes da Pesquisa}

A pesquisa teve por alvo todas as pessoas que trabalhavam na Biblioteca Central da UnB, excetuando-se aquelas que ocupavam funções gerenciais, uma vez que se pretendia investigar os estilos gerenciais presentes na BCE, sob a ótica dos subordinados.

De acordo com dados fornecidos pela secretaria, à época da pesquisa, trabalhavam na BCE 172 pessoas. Dessa população, foram excluídas 38 pessoas, sendo 14 porque ocupavam funções gerenciais e 24 porque estavam ausentes do ambiente de trabalho por motivos diversos como licença médica, licença de capacitação etc.

Dessa forma, foram distribuídos questionários para um universo de 134 sujeitos. Desse quantitativo, 103 pessoas responderam ao questionário, perfazendo um total de $\mathbf{7 7 \%}$ de taxa de devolução.

Dos 103 questionários devolvidos, quatro foram descartados por apresentarem incorreções. Sendo assim, trabalhou-se efetivamente com um total de 99 sujeitos. As características predominantes que marcam o perfil demográfico dos participantes da pesquisa foram as seguintes:

- Sexo: feminino $(58,6 \%)$;

- Faixa Etária: $\geq 37$ anos (32,3);

- Estado Civil: solteiro (54,5\%);

- Escolaridade: superior incompleto: $(37,4 \%)$;

- Vínculo Funcional: estagiário (44,4\%);

- Tempo de Serviço na UnB: $\leq 2$ anos $(37,4 \%)$

- Tempo de Serviço na Biblioteca Central: $\leq 2$ anos $(41,4 \%)$.

\subsection{Instrumento da Pesquisa}

Foi utilizada a Escala de Avaliação dos Estilos Gerenciais (EAEG), construída e validada por Melo (2001). A EAEG é composta por 19 itens para serem respondidos numa escala tipo "Likert", de cinco pontos, variando de "1- nunca age assim" até "5- sempre age assim". Os 19 itens da escala foram agrupados em três fatores denominados: Fator 1 "Relacionamento", Fator 2 "Tarefa" e Fator 3 "Situação".

Foram agregados à EAEG, mais sete perguntas para construção do perfil demográfico dos respondentes envolvendo: gênero, idade, escolaridade, estado civil, categoria funcional, tempo de serviço na UnB e tempo de serviço na BCE. 


\subsection{Procedimentos de Coleta de Dados}

Os questionários foram impressos e entregues pessoalmente a cada um dos participantes da pesquisa, com a informação de que os dados coletados seriam sigilosos e tratados de forma agregada, sem a identificação do respondente. Os participantes foram instruídos a devolverem o questionário preenchido na urna colocada na entrada privativa dos funcionários da biblioteca.

\subsection{Procedimentos de Análise de Dados}

Os dados coletados dos questionários de pesquisa foram analisados usando o Statistical Package for Social Sciences (SPSS). Usando o SPSS foram feitas estatísticas descritivas e inferenciais. 


\section{CAPÍTULO 3 - APRESENTAÇÃO E DISCUSSÃO DOS RESULTADOS}

A presente pesquisa teve por objetivo geral analisar os estilos gerenciais presentes na biblioteca central de uma Instituição Federal de Ensino Superior (IFES). Para alcançá-lo foram estabelecidos três objetivos específicos:

1. Fazer uma revisão da literatura sobre o tema "liderança", com ênfase em "estilos gerenciais".

2. Identificar os estilos gerenciais presentes na biblioteca central de uma IFES, comparando-os com os descritos pela literatura.

O primeiro objetivo específico foi atingido no Capítulo 1 com a revisão de literatura. Neste Capítulo serão apresentados e discutidos os resultados referentes ao segundo objetivo específico proposto para a pesquisa.

\section{1 - Validação da Estrutura Empírica do Instrumento}

Conforme mencionado no subitem 2.4, foi utilizada a Escala de Avaliação dos Estilos Gerenciais (EAEG), construída e validada por Melo (2001), para se identificar os estilos gerenciais presentes na Biblioteca Central da Universidade de Brasília. Os três fatores encontrados por Melo (2001) quando da validação do instrumento representam os seguintes estilos gerenciais:

- Fator 1 - Estilo gerencial voltado para o "Relacionamento". Agrupa os itens referentes ao comportamento da chefia retratando a sua disponibilidade para ouvir os subordinados, dar atenção a eles, interessar-se pelo que sentem etc.

- Fator 2 - Estilo gerencial voltado para a "Tarefa". Reúne itens referentes ao comportamento da chefia caracterizado pela valorização à hierarquia, pelo cumprimento de prazos etc.

- Fator 3 - Representa o estilo gerencial voltado para a "Situação". Neste Fator os itens são referentes ao comportamento da chefia caracterizado pela flexibilidade na maneira de lidar com o subordinado.

$\mathrm{Na}$ presente pesquisa, não foi possível fazer uma nova Análise Fatorial para confirmar a estrutura empírica encontrada por Melo (2001), uma vez que o total de participantes não 
atendia ao pressuposto do número mínimo de sujeitos necessário à realização desse tipo de estatística. Entretanto, foi possível fazer uma análise de confiabilidade para se verificar a consistência interna dos itens do instrumento. A Tabela 1 mostra os índices do Alpha de Cronbach encontrados na validação original do instrumento e os encontrados nesta pesquisa:

Tabela 1 - Índices de Consistência Interna dos Itens da EAEG

\begin{tabular}{|c|c|c|}
\hline \multirow{2}{*}{ Fator } & Pesquisa Original & Pesquisa Atual \\
\cline { 2 - 3 } Relacionamento & Alpha de Cronbach & Alpha de Cronbach \\
\hline Tarefa & $\alpha=0,94$ & 0,80 \\
\hline Situação & $\alpha=0,70$ & 0,70 \\
\hline
\end{tabular}

Os dados da Tabela 1 mostram que na validação do instrumento feita por Melo (2001), os itens dos três fatores apresentaram bons índices de consistência interna, com exceção do Fator 2 (Tarefa) que apresentou um índice um pouco mais baixo. A nova análise feita com os dados da pesquisa atual encontrou índices um pouco mais baixos com relação ao Fator 1 (Relacionamento), índice semelhante no Fator 2 (Tarefa) e índice abaixo do encontrado originalmente no Fator 3 (Situação).

\section{2 - Percepção dos Estilos Gerenciais da BCE}

A Tabela 2 apresenta as médias e os desvios padrões correspondentes a cada um dos estilos gerenciais que foram percebidos pelos trabalhadores da Biblioteca Central da UnB:

Tabela 2 - Média e Desvio Padrão dos Estilos Gerenciais

\begin{tabular}{|c|c|c|}
\hline Fator & Média & Desvio Padrão \\
\hline Relacionamento & 4,00 & 1,00 \\
\hline Tarefa & 3,92 & 0,60 \\
\hline Situação & 3,94 & 0,70 \\
\hline
\end{tabular}

Os resultados apresentados na Tabela 2 apontam que, na percepção dos trabalhadores que participaram da pesquisa, os três estilos gerenciais estão presentes na Biblioteca Central da UnB.

- Fator 1 - Nesse Fator, que representa o estilo gerencial voltado para o Relacionamento, a média foi 4,00, que corresponde ao ponto "freqüentemente age assim". Isso significa que, na percepção dos trabalhadores da BCE, os gerentes 
mostram consideração para com os subordinados. O desvio padrão 1,00 aponta que houve certa homogeneidade nas respostas dadas pelos participantes da pesquisa aos itens desse Fator.

- Fator 2 - Este Fator representa o estilo gerencial voltado para a Tarefa. Nele, a média foi 3,92, situando-se entre os pontos "Ocasionamente age assim" e “freqüentemente age assim”, porém bem mais próximo desse último. Isso significa que, na percepção dos trabalhadores da $\mathrm{BCE}$, os gerentes também se preocupam com aspectos relacionados ao cumprimento da tarefa, com valorização de hierarquia, cumprimento de prazos e outros. O desvio padrão de 0,60 aponta que houve alta concordância nas respostas dadas pelos participantes da pesquisa aos itens desse Fator.

- Fator 3 - Representa o estilo gerencial voltado para a Situação. Nesse Fator, a média foi 3,94, ficando entre os pontos "Ocasionamente age assim" e “freqüentemente age assim", porém bem mais próximo do ponto 4. Isso significa que, na percepção dos trabalhadores da $\mathrm{BCE}$, os gerentes também apresentam um comportamento gerencial flexível com relação aos seus subordinados. O desvio padrão de 0,70 aponta que houve alta concordância nas respostas dadas pelos participantes da pesquisa aos itens desse Fator.

Melo (2001) lembra que nos estudos sobre liderança desenvolvidos pela Ohio State University, os pesquisadores concluíram que os dois estilos gerenciais pesquisados Consideração (equivalente ao Relacionamento) e Estrutura Inicial (equivalente à Tarefa) são distintos e não fazem parte de um contínuo. Isso significa que as chefias podem apresentar um ou outro estilo ou ambos. Isso é verdadeiro, também, para o estudo conduzido por Melo (2001) cujo instrumento agregou mais uma outra dimensão - a situacional.

Dessa forma, os resultados encontrados nesta pesquisa, que utilizou o instrumento de Melo (2001) e apontou que os três estilos gerenciais são praticados na Biblioteca Central da Universidade de Brasília, reforçam os achados da literatura.

Apesar das médias dos escores fatoriais terem se mostrado bastante semelhantes, foi realizada uma análise de variância para se confirmar se havia realmente essa igualdade nas médias. O resultado do teste $\mathrm{T}$ de Student mostrou que não houve diferença significativa entre as médias dos três fatores - Relacionamento, Tarefa e Situação. Mesmo para uma amostra com 99 indivíduos, que no contexto desse tipo de teste é considerada grande, os resultados não foram estatisticamente significativos. Esse resultado difere daquele encontrado por Melo 
(2001) em pesquisa conduzida na Empresa Brasileira de Correios e Telégrafos, onde houve predominância dos estilos gerenciais relacionados à Tarefa e à Situação.

Foram realizados, também, testes de comparação das médias para verificar se havia diferença de percepção dos estilos gerenciais com relação ao perfil demográfico dos respondentes. Os resultados foram os seguintes:

\section{a) Gênero}

Os dados da Tabela 3 mostram a comparação das médias de homens e mulheres quanto aos estilos gerenciais percebidos:

Tabela 3 - Resultados do teste t de Student da variável gênero quanto aos estilos gerenciais

\begin{tabular}{|c|c|c|c|c|c|c|c|c|}
\hline Fatores & Gênero & $\mathrm{M}$ & $\mathrm{t}$ & $\mathrm{Gl}$ & Sig. & $\begin{array}{l}\text { Dif. } \\
\text { Médias }\end{array}$ & $\begin{array}{c}\text { IC } 95 \%- \\
\text { Inf. }\end{array}$ & $\begin{array}{c}\text { IC 95\% - } \\
\text { Sup. }\end{array}$ \\
\hline \multirow[t]{2}{*}{ Relacionamento } & Homem & 3,92 & \multirow[t]{2}{*}{$-0,76$} & \multirow[t]{2}{*}{96} & \multirow[t]{2}{*}{0,45} & \multirow[t]{2}{*}{$-0,16$} & \multirow[t]{2}{*}{$-0,58$} & \multirow[t]{2}{*}{0,26} \\
\hline & Mulher & 4,08 & & & & & & \\
\hline \multirow[t]{2}{*}{ Tarefa } & Homem & 3,90 & \multirow[t]{2}{*}{$-0,25$} & \multirow[t]{2}{*}{96} & \multirow[t]{2}{*}{0,80} & \multirow[t]{2}{*}{$-0,03$} & \multirow[t]{2}{*}{$-0,29$} & \multirow[t]{2}{*}{0,22} \\
\hline & Mulher & 3,93 & & & & & & \\
\hline \multirow[t]{2}{*}{ Situacional } & Homem & 3,84 & \multirow[t]{2}{*}{$-1,15$} & \multirow[t]{2}{*}{96} & \multirow[t]{2}{*}{0,25} & \multirow[t]{2}{*}{$-0,17$} & \multirow[t]{2}{*}{$-0,46$} & \multirow[t]{2}{*}{0,12} \\
\hline & Mulher & 4,00 & & & & & & \\
\hline
\end{tabular}

Conforme pode ser observado na Tabela 3, há pequenas diferenças nas médias de homens e mulheres nos três tipos de estilos gerenciais. Por meio do teste $\mathrm{t}$ de Student verificou-se que as diferenças observadas nas médias de homens e mulheres não são significativas $(\mathrm{p}>0,05)$. Ou seja, pode-se dizer com $95 \%$ de confiança que as diferenças de percepção observadas nas médias são devidas ao acaso ou ao erro amostral.

Esse resultado difere do encontrado no contexto estudado por Melo (2001), onde houve diferença de percepção entre homens e mulheres com relação aos estilos Relacionamento e Situacional. Na pesquisa de Melo, os homens perceberam o estilo Relacionamento mais fortemente do que as mulheres, o mesmo ocorrendo com relação ao estilo Situacional. Os resultados daquela pesquisa demonstraram que, nos Correios, ao contrário da Biblioteca Central da $\mathrm{UnB}$, a relação das chefias com os homens e com as mulheres parece não se desenvolver da mesma maneira, explicando as diferenças de percepção. 


\section{b) Faixa Etária}

Na Tabela 4 são apresentados os resultados da comparação das médias de faixa etária quanto aos estilos gerenciais percebidos:

Tabela 4 - Resultados do teste ANOVA da variável faixa etária quanto aos estilos gerenciais

\begin{tabular}{|c|c|c|c|c|}
\hline Fator & Faixa Etária & $\mathbf{N}$ & Média & Desvio Padrão \\
\hline \multirow{3}{*}{ Relacionamento } & $<=23$ & 31 & 4,23 & 1,14 \\
\cline { 2 - 5 } & $24-36$ & 31 & 3,86 & 1,20 \\
\cline { 2 - 5 } & $37+$ & 32 & 3,92 & 0,76 \\
\cline { 2 - 5 } & Total & 94 & 4,00 & 1,05 \\
\hline \multirow{3}{*}{ Tarefa } & $<=23$ & 31 & 3,90 & 0,71 \\
\cline { 2 - 5 } & $24-36$ & 31 & 3,93 & 0,66 \\
\cline { 2 - 5 } & $37+$ & 32 & 3,95 & 0,54 \\
\cline { 2 - 5 } & Total & 94 & 3,93 & 0,63 \\
\hline \multirow{3}{*}{ Situacional } & $<=23$ & 31 & 4,00 & 0,63 \\
\cline { 2 - 5 } & $24-36$ & 31 & 3,79 & 0,76 \\
\cline { 2 - 5 } & $37+$ & 32 & 3,98 & 0,77 \\
\cline { 2 - 5 } & Total & 94 & 3,92 & 0,72 \\
\hline
\end{tabular}

Uma análise dos dados apresentados na Tabela 4 mostra que há pequenas diferenças nas médias dos grupos de faixa etária comparados nos três tipos de estilos gerenciais. Com a realização do teste $\mathrm{F}$ da ANOVA verificou-se que as diferenças observadas nas médias dos grupos de faixa etária não são significativas para o Fator Relacionamento $(\mathrm{F}=1,17)$ e para $\mathrm{o}$ Fator Situacional $(\mathrm{F}=0,83)$, mas são significativas para o Fator Tarefa $(\mathrm{F}=0,045)$ que teve $\mathrm{p}<0,05$.

O resultado encontrado sinaliza que os trabalhadores da BCE que estão numa faixa etária menor percebem o estilo gerencial Tarefa como mais forte do que aqueles de uma faixa etária mais elevada. Isso talvez possa ser explicado pelo fato de que as pessoas mais jovens são também aquelas com menor tempo de serviço e de experiência.

Esse perfil acaba favorecendo a percepção de um estilo gerencial mais voltado para a tarefa, na medida em que atrai uma atenção maior por parte do dirigente para a supervisão do trabalho a ser realizado. Não há relato sobre a comparação de médias entre faixa etária e os três estilos gerenciais no trabalho de Melo (2001). Assim, para essa variável demográfica específica, não foi possível comparar os resultados entre as duas pesquisas realizadas.

\section{c) Escolaridade}

Os dados da Tabela 5, apresentados a seguir, mostram a comparação das médias de nível de escolaridade quanto aos estilos gerenciais percebidos: 
Tabela 5 - Resultados do teste ANOVA da variável escolaridade quanto aos estilos gerenciais

\begin{tabular}{|c|l|c|c|c|}
\hline Fator & \multicolumn{1}{|c|}{ Escolaridade } & N & Média & Desvio Padrão \\
\hline \multirow{4}{*}{ Relacionamento } & Ensino Médio Completo & 25 & 3,79 & 0,67 \\
\cline { 2 - 5 } & Superior Incompleto & 37 & 4,29 & 1,28 \\
\cline { 2 - 5 } & Superior Completo & 31 & 3,83 & 0,97 \\
\cline { 2 - 5 } & Pós-graduação & 6 & 4,22 & 0,23 \\
\cline { 2 - 5 } & Total & 99 & 4,01 & 1,03 \\
\hline \multirow{3}{*}{ Tarefa } & Ensino Médio Completo & 25 & 3,91 & 0,61 \\
\cline { 2 - 5 } & Superior Incompleto & 37 & 3,94 & 0,59 \\
\cline { 2 - 5 } & Superior Completo & 31 & 3,87 & 0,71 \\
\cline { 2 - 5 } & Pós-graduação & 6 & 4,08 & 0,49 \\
\cline { 2 - 5 } & Total & 99 & 3,92 & 0,62 \\
\hline \multirow{3}{*}{ Situacional } & Ensino Médio Completo & 25 & 3,91 & 0,69 \\
\cline { 2 - 5 } & Superior Incompleto & 37 & 4,02 & 0,63 \\
\cline { 2 - 5 } & Superior Completo & 31 & 3,81 & 0,85 \\
\cline { 2 - 5 } & Pós-graduação & 6 & 4,17 & 0,47 \\
\cline { 2 - 5 } & Total & 99 & 3,94 & 0,71 \\
\hline
\end{tabular}

Conforme pode ser observado na Tabela 5, há pequenas diferenças nas médias dos grupos comparados nos três tipos de estilos gerenciais. Por meio do teste $\mathrm{F}$ da ANOVA verificou-se que as diferenças observadas nas médias dos grupos de escolaridade não são significativas, a saber: para o Fator Relacionamento $(\mathrm{F}=1,76)$; Fator Tarefa $(\mathrm{F}=0,23)$ e Fator Situacional $(F=0,75)$, todos com $p>0,05$.

Esse resultado também diferiu daquele encontrado por Melo (2001), onde os empregados com nível de escolaridade menor perceberam o estilo gerencial Tarefa como mais forte, do que os empregados com nível de escolaridade maior.

\section{d) Tempo de Serviço na Biblioteca Central}

Os dados da Tabela 6, apresentados a seguir, mostram a comparação das médias de tempo de serviço na Biblioteca Central (BCE) quanto aos estilos gerenciais percebidos:

Tabela 6 - Resultados do teste ANOVA da variável tempo de serviço na BCE quanto aos estilos gerenciais

\begin{tabular}{|c|c|c|c|c|}
\hline Fator & Tempo na BCE & $\mathbf{N}$ & $\mathbf{M}$ & Desvio Padrão \\
\hline \multirow{3}{*}{ Relacionamento } & $<=2$ & 41 & 4,21 & 1,05 \\
\cline { 2 - 5 } & $3-10$ & 27 & 3,80 & 0,94 \\
\cline { 2 - 5 } & $11+$ & 26 & 3,74 & 0,75 \\
\cline { 2 - 5 } & Total & 94 & 3,96 & 0,96 \\
\hline \multirow{4}{*}{ Tarefa } & $<=2$ & 41 & 3,97 & 0,64 \\
\cline { 2 - 5 } & $3-10$ & 27 & 3,90 & 0,75 \\
\cline { 2 - 5 } & $11+$ & 26 & 3,84 & 0,49 \\
\cline { 2 - 5 } & Total & 94 & 3,91 & 0,64 \\
\hline \multirow{3}{*}{ Situacional } & $<=2$ & 41 & 4,03 & 0,63 \\
\cline { 2 - 5 } & $3-10$ & 27 & 3,98 & 0,84 \\
\cline { 2 - 5 } & $11+$ & 26 & 3,74 & 0,74 \\
\cline { 2 - 5 } & Total & 94 & 3,94 & 0,73 \\
\hline
\end{tabular}


A Tabela 6 demonstra haver pequenas diferenças nas médias dos grupos com diferentes tempos de serviço na BCE comparados nos três tipos de estilos gerenciais. Entretanto, por meio do teste $\mathrm{F}$ da ANOVA verificou-se que as diferenças observadas nas médias dos grupos não são significativas: Fator Relacionamento $(\mathrm{F}=2,53)$; Fator Tarefa $(\mathrm{F}=0,33)$ e Fator Situacional $(\mathrm{F}=1,34)$, todos com $\mathrm{p}>0,05$. Isso significa que a percepção dos estilos gerenciais não diferiu em relação ao tempo de serviço que os participantes da pesquisa tinham na Universidade de Brasília. A pesquisa de Melo (2001) não realizou comparação entre a variável tempo de serviço e os três estilos gerenciais. 


\section{CONCLUSÃO}

Este estudo teve por objetivo analisar os estilos gerenciais presentes na biblioteca central de uma universidade pública, por meio da aplicação da Escala de Avaliação dos Estilos Gerenciais (EAEG), construída e validada por Melo (2001).

Os três estilos gerenciais investigados - Relacionamento, Tarefa e Situacional - foram percebidos pelos participantes da pesquisa, mas a análise dos dados mostrou que não houve diferença significativa entre as médias encontradas. Isso significa que na Biblioteca Central da Universidade de Brasília, onde foi realizada a pesquisa, os três estilos gerenciais são praticados sem que ocorra a predominância de nenhum deles.

Esse resultado diferiu daquele encontrado por Melo (2001) em pesquisa conduzida na Empresa Brasileira de Correios e Telégrafos, onde houve predominância dos estilos gerenciais voltados para o Relacionamento e para a Situação.

Com o propósito de se investigar se havia diferença na percepção dos estilos gerenciais em função do perfil demográfico, foram realizados testes de comparação das médias considerando as variáveis gênero, faixa etária, escolaridade e tempo de serviço na Biblioteca Central (BCE). Os resultados mostraram que a diferença entre as médias dos grupos analisados para gênero, escolaridade e tempo de serviço na BCE quanto aos três estilos gerenciais não era significativa. Entretanto, com relação à faixa etária, a diferença entre as médias foi significativa $(\mathrm{p}<0,05)$ para o Fator Tarefa, indicando que os trabalhadores com menor faixa etária percebiam mais fortemente esse estilo gerencial.

Estudar o comportamento gerencial das pessoas que trabalham dentro das instituições de ensino ainda é um campo que pode e merece ser mais bem explorado, a exemplo do que é feito no contexto das organizações de trabalho. Além de possuírem uma configuração meritocrática, as instituições de ensino carregam certas especificidades que as diferenciam de outras formas organizacionais e, portanto, merecem receber uma atenção maior por parte dos pesquisadores.

Silva, Cunha e Possamai (2001), em artigo que pleiteia mais estudos sobre liderança dentro do contexto acadêmico, destacam que as pessoas que exercem cargos gerenciais são responsáveis pela formulação, articulação e execução das estratégias e movimentos táticos das organizações. Elas não apenas definem as grandes estratégias da organização, mas também articulam os vários subsistemas organizacionais visando atingir determinados objetivos. As habilidades gerenciais determinam o sucesso da organização. 
Uma das limitações do presente estudo está no fato de que a pesquisa envolveu apenas os trabalhadores de uma das várias unidades funcionais da universidade, no caso, a Biblioteca Central. Sugere-se, como agenda futura de pesquisa, que este trabalho possa estimular o interesse de outros pesquisadores para expandir o estudo, abraçando outras unidades funcionais da universidade, bem como os membros do corpo docente que desempenham funções gerenciais. 


\section{REFERÊNCIAS}

ANTONELLO, C. S.; RUAS, R. Formação gerencial: pós-graduação lato-sensu e o papel das comunidades de prática. RAC- Revista de Administração Contemporânea. Rio de Janeiro. V. 9, n. 2., abr./jun. 2005. p. 35-38.

BERGAMINI, C. W. Liderança: administração do sentido. São Paulo, Atlas, 1994.

BLAKE, R.R.; MOUTON, J.S. O Grid Gerencial. 3. ed. São Paulo: Pioneira, 1978.

CHOWDHURY, S. Administração no século XXI: o estilo de gerência hoje e no futuro. São Paulo : Pearson Education, 2003.

CABRAL, P. M. F.; ROCHA, C. B.; SEMINOTTI, N. Como os gestores se apropriam da emoção no desenvolvimento de suas competências de liderança. In: ENCONTRO DA ANPAD-EnANPAD, 31, 2007. Rio de Janeiro : ANPAD, 2007. CD-ROM.

CARVALHO, I. M.; MEDEIROS, J. J. Aspectos da liderança para criação de conhecimento em uma empresa de alta tecnologia. In: ENCONTRO EnANPAD, 30, $2006 . \quad$ Salvador : ANPAD, 2007. CD-ROM.

COCHIA, C. B. R.; CAETANO JÚNIOR, J. M. V.; BORGES, W. A . Liderança em uma concessionária de motocicletas. In: ENCONTRO ANPAD-EnANPAD, 31, 2007. Rio de Janeiro : ANPAD, 2007. CD-ROM

DRUCKER, P. Administração para o futuro: os anos 90 e a virada do século. São Paulo : Pioneira Thompson, 2001.

HAMPTON, D. R Administração: comportamento organizacional. São Paulo : McGrawHill, 1990.

JUNQUILHO, G. S. Condutas gerenciais e suas raízes: uma proposta de análise à luz da Teoria da Estruturação. RAC-Revista de Administração Contemporânea, Rio de Janeiro, v. 7, 2003. p. 101-117. Edição especial

MARCELINO, G. F. Gestão estratégica da universidade: a construção da FACE. Brasília : Editora da Universidade de Brasília, 2004.

MARRA, A .V.; LOPES, M. C. O Prática social dos gerentes universitários em uma instituição pública. RAC-Revista de Administração Contemporânea. Rio de Janeiro. v. 9, n. 3, jul./set. 2005. p. 9-23.

MAXIMINIANO, Antônio César A. Teoria geral da administração: escola científica a competitividade em economia globalizada. São Paulo : Atlas, 1997.

MELO, E. A de A. Comprometimento organizacional estilos gerenciais e poder organizacional: um estudo relacional. 2001. 120 f. Dissertação (Mestrado em Psicologia)Universidade de Brasília, Brasília, 2001. 
MOTTA, F. C. P. Teoria geral da administração. São Paulo : Pioneira, 2002.

MOTTA, P. R.. Gestão contemporânea: a ciência e a arte de ser diferente. 7. ed. Rio de Janeiro : Record, 1996.

ROBBINS, S. P. Administração: mudanças e perspectivas. São Paulo : Pioneira Thompson, 2001.

Comportamento organizacional. 9. ed. São Paulo : Pioneira Thompson, 2002.

ROWE, G. Liderança estratégica e criação de valor. RAE- Revista de administração de Empresas. São Paulo. v. 42, n. 1, jan./mar. 2002. p. 7-19.

SCHMITT, E. C; LEAL, A P. Liderança, mito e identificação: faces do controle afetivo nas organizações de trabalho. In: ENCONTRO EnANPAD, 30, 2006. Salvador: ANPAD, 2006. CD-ROM.

SILVA, M. A da; CUNHA, C. J. C.; POSSAMAI, F. O que os professores aprendem para dirigir unidades universitárias: o caso da UFSC. In: ENCONTRO EnANPAD, 25, 2001. Salvador : ANPAD, 2001. CD_ROM

SILVA, W.; LAROS, J. A.; MOURÃO, L. Como atuam os gerentes? o desenvolvimento de uma medida. In: ENCONTRO ANPAD-EnANPAD, 31, 2007. Rio de Janeiro: ANPAD, 2007. CD-ROM.

SIQUEIRA, M. V. S. Gestão de pessoas e dicurso organizacional: crítica a relação indivíduos - empresas nas organizações contemporâneas. Goiânia : UCG, 2006.

STONER, J.A.F.; FREEMAN, R.E. Administração. 5ed. Rio de Janeiro: LTC, 1999.

VERGARA, S. C. Projetos e relatórios de pesquisa em administração. 6. ed. São Paulo : Atlas, 2005.

WAGNER III, J. A., HOLLENBECK, J. R. Comportamento organizacional: criando vantagem competitiva. São Paulo : Saraiva, 2002. 